Article

\title{
Finite Element Analysis for Fatigue Damage Reduction in Metallic Riveted Bridges Using Pre-Stressed CFRP Plates
}

Elyas Ghafoori ${ }^{1,4, *}$, Gary S. Prinz ${ }^{2}$, Emmanuel Mayor $^{3}$, Alain Nussbaumer ${ }^{3}$, Masoud Motavalli ${ }^{1}$, Andrin Herwig ${ }^{1}$ and Mario Fontana ${ }^{4}$

1 Empa, Swiss Federal Laboratories for Materials Science and Technology, Structural Engineering, Research Laboratory, Dübendorf CH-8600, Switzerland;

E-Mails: masoud.motavalli@empa.ch (M.M.); andrin.herwig@empa.ch (A.H.)

2

Department of Civil Engineering, University of Arkansas, Fayetteville, AR 72701, USA;

E-Mail: prinz@uark.edu

3 EPFL, Swiss Federal Institute of Technology Lausanne, Steel Structure Laboratory (ICOM), Lausanne CH-1015, Switzerland; E-Mails: emmanuel.mayor@outlook.com (E.M.); alain.nussbaumer@epfl.ch (A.N.)

4 ETHZ, Swiss Federal Institute of Technology Zürich, Institute of Structural Engineering (IBK), Zürich CH-8093, Switzerland; E-Mail: mario.fontana@ethz.ch

* Author to whom correspondence should be addressed; E-Mail: elyas.ghafoori@empa.ch or ghafoori@ibk.baug.ethz.ch; Tel.: +41-58-765-4935; Fax: +41-58-765-6955.

Received: 24 December 2013; in revised form: 6 March 2014 / Accepted: 26 March 2014 / Published: 11 April 2014

\begin{abstract}
Many old riveted steel bridges remain operational and require retrofit to accommodate ever increasing demands. Complicating retrofit efforts, riveted steel bridges are often considered historical structures where structural modifications that affect the original construction are to be avoided. The presence of rivets along with preservation requirements often prevent the use of traditional retrofit methods, such as bonding of fiber reinforced composites, or the addition of supplementary steel elements. In this paper, an un-bonded post-tensioning retrofit method is numerically investigated using existing railway riveted bridge geometry in Switzerland. The finite element (FE) model consists of a global dynamic model for the whole bridge and a more refined sub-model for a riveted joint. The FE model results include dynamic effects from axle loads and are compared with field measurements. Pre-stressed un-bonded carbon fiber reinforced plastic (CFRP) plates will be considered for the strengthening elements. Fatigue critical regions of the bridge are identified, and the effects of the un-bonded post-tensioning method with different
\end{abstract}


pre-stress levels on fatigue susceptibility are explored. With an applied $40 \%$ CFRP pre-stress, fatigue damage reductions of more than $87 \%$ and $85 \%$ are achieved at the longitudinal-to-cross beam connections and cross-beam bottom flanges, respectively.

Keywords: finite element model; fatigue damage; metallic railway riveted bridge; CFRP; un-bonded post-tensioning

\section{Introduction}

Steel structures subjected to repeated loads will ultimately fail through a process of material fatigue, with the material fatigue-life (number of resisted repeated load cycles) being directly related to the repeated load value. Higher loads typically correspond with lower fatigue-life. Many old riveted bridges still in operation are subjected to ever increasing loads and require retrofit to extend the remaining fatigue-life.

Many commonly used retrofit methods are prohibited or difficult to install on riveted bridges. Due to historic preservation requirements, municipalities often prohibit alteration of riveted steel bridges, including welding or bolting of additional steel elements. Additionally, retrofits that require some form of bonding or gluing, such as attachment of fiber reinforced composites, are difficult due to the presence of unsmooth surfaces such as protruding rivet heads. Retrofit systems that do not require alteration of the existing structure (drilling of holes, addition of welds, etc.) or bonding/gluing of external members, are desired.

An un-bonded post-tensioning system using carbon fiber reinforced polymer (CFRP) plates, recently developed at the Swiss Federal Laboratories for Materials Science and Technology (Empa), may provide increased strength and increased fatigue life to riveted bridges while accommodating preservation requirements [1]. Compared to standard post-tensioning techniques (strands or bars), CFRP materials have been used for many retrofit solutions due to a high strength-to-weight ratio, high corrosion resistance and excellent fatigue performance. In the un-bonded CFRP system, post-tensioned CRFP plates are attached to clamps, which are then attached to beams using only friction. Unlike bonded CFRP plates, rivet heads do not interfere with the un-bonded system thanks to the eccentricity between the CFRP plate and beam attachment. Also, no permanent modifications, such as holes or welds, are added to the existing structure. By attaching the CFRP system to the underside of a riveted bridge beam, initial compressive stresses could be introduced in the lower chord, thus reducing the applied tensile stress range and fatigue damage during loading.

In this paper, the effect of the un-bonded CFRP post-tensioning retrofit system on the fatigue susceptibility of an existing bridge in Münchenstein, Switzerland, is explored. Analytical models are used to determine critical fatigue locations and to investigate the relative effects of the post-tensioning retrofit on these locations. The paper begins by describing the modeling methods for a global bridge model including an overview of the bridge geometry and element types, materials, loading, simulation of the CFRP post-tensioning retrofit, and sub-modeling of a riveted joint. Following, fatigue analyses with and without the retrofit are presented, considering multiple CFRP pre-stress levels. The aim of the joint sub-modeling is to provide more details about the location of possible fatigue initiation. Conclusions about the effects of the post-tensioning retrofit method on bridge fatigue performance are provided. 


\section{Modeling Methods}

\subsection{Global Model}

A global model simulating an entire bridge geometry is created to analyze the entire system response and help identify fatigue critical locations. The following subsections describe the bridge geometry and analysis methods for the global bridge model, including: element types, boundary conditions, material properties, and loading used.

\subsubsection{Geometry and Element Type}

The global model geometry is based on construction documents of an existing riveted railway bridge in Münchenstein, Switzerland. The bridge consists of two longitudinal trusses connected by various cross-beams and cross-bracings. The existing bridge supports are skewed at nearly 45 degrees, creating a singly symmetric geometry. Figure 1 shows the basic bridge geometry, having a width and individual truss-bay length of around $5 \mathrm{~m}$. Individual brace geometries for the first five bays are also presented in Figure 1 (note that only five bays are presented due to symmetry).

Figure 1. Münchenstein railway bridge basic geometry.
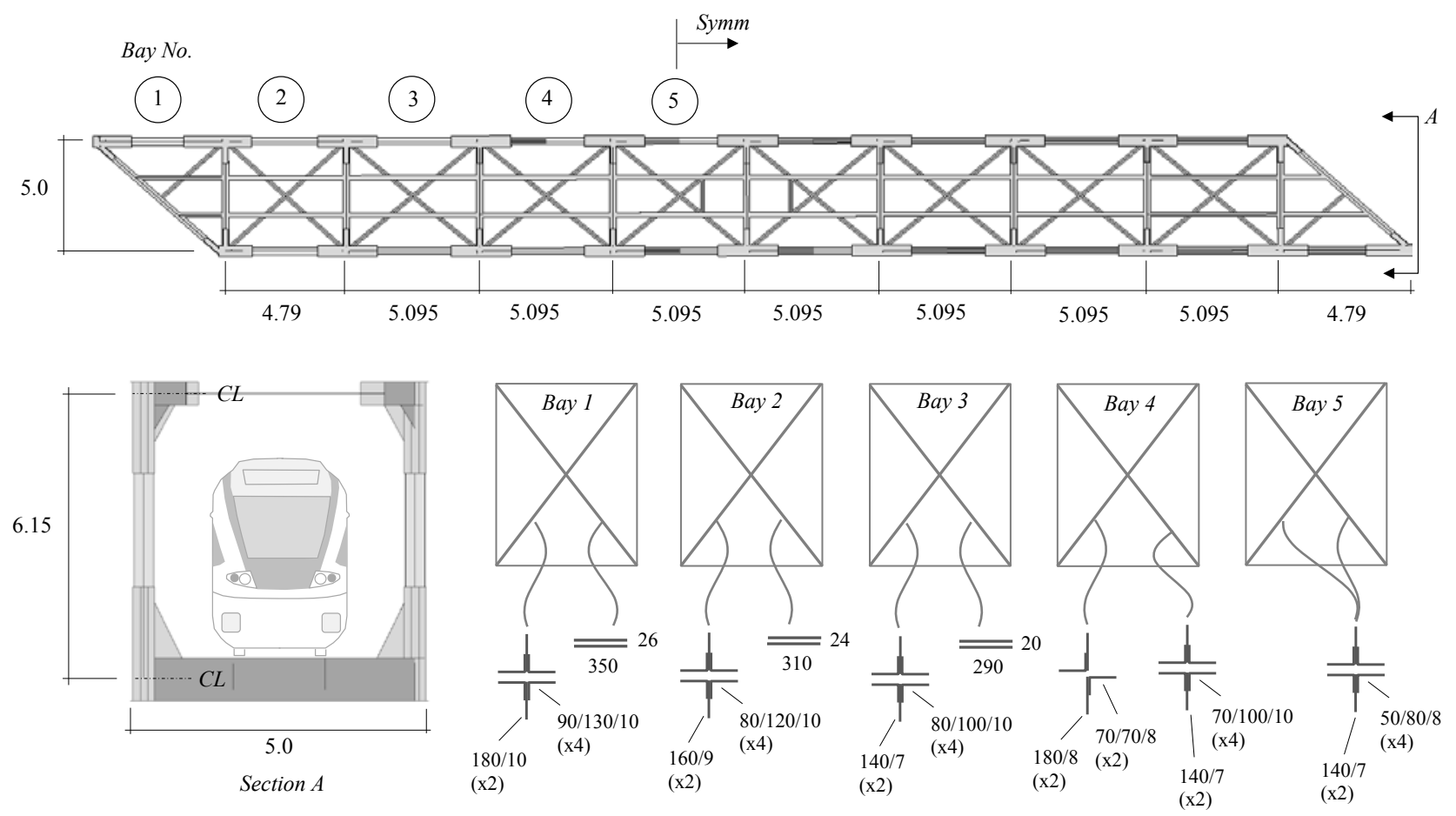

In order to determine potential fatigue critical locations, detailed stress states within local member regions are required. A global bridge model having refined geometry within the connection regions is used. In the global bridge model, four-node linear shell elements model all geometries within the connection regions (potential critical locations). By using shell elements within the connection regions, a more realistic representation of connection rigidity and subsequent force distribution can be obtained. Additionally, by using shell elements, localized stress distributions and concentrations resulting from local geometric deformations can be determined. Outside the connection regions (where fatigue is of 
little concern), beam elements are used to reduce computational expense. An example of the connection geometry within the global bridge model is presented in Figure 2, showing both shell and beam elements. All shell elements correspond to the actual member geometry centerlines. All shell element thicknesses are assigned based on nominal member dimensions. ABAQUS [2] is used for all analyses.

Figure 2. Bridge model element type.

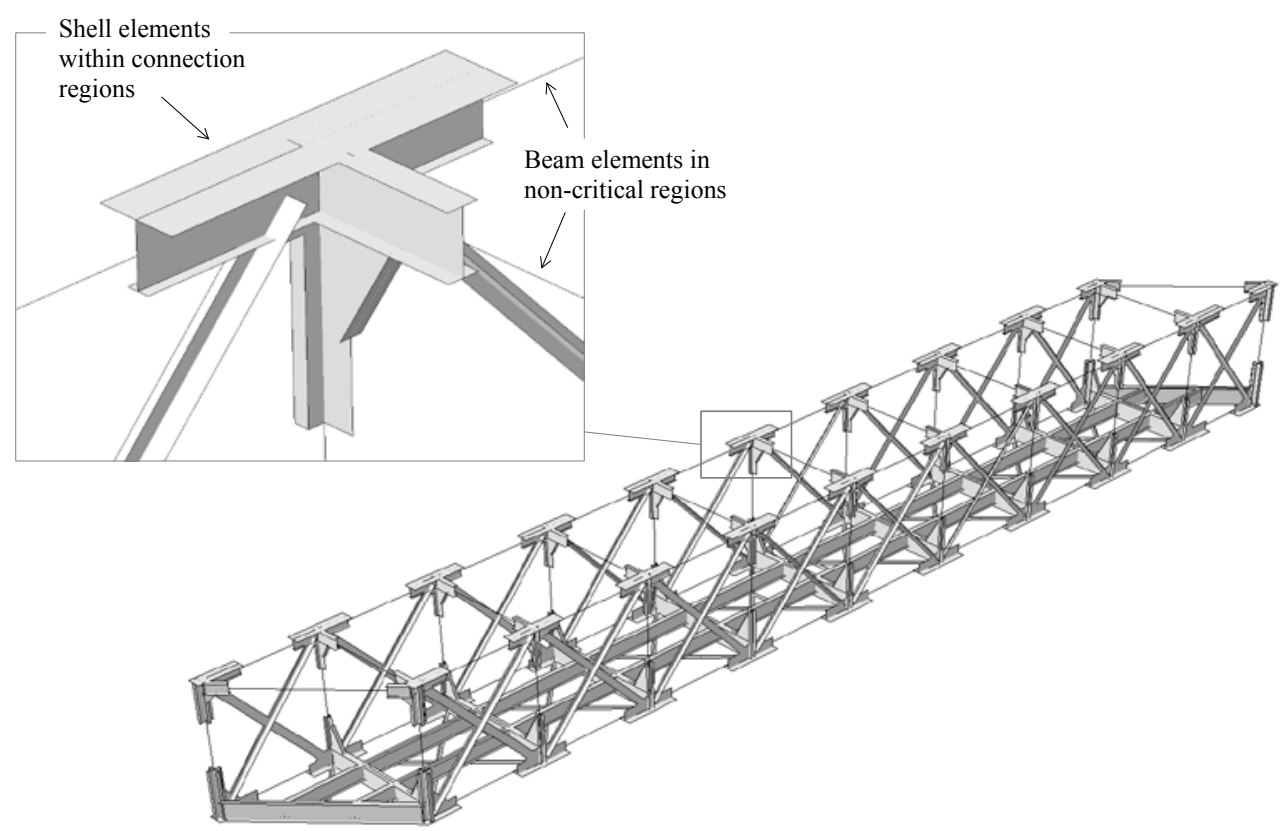

\subsubsection{Mesh and Boundary Conditions}

Mesh size can affect the accuracy and computational expense of an analysis. Typically, smaller element size is associated with higher computational expense. In the global bridge model, connection regions, braces, and the entire longitudinal beams, have four-node linear shell elements at a general mesh size of $50 \mathrm{~mm}$. While $50 \mathrm{~mm}$ is a somewhat large element size for modeling of a standard structural connection, in the context of an entire bridge with a span of over $45 \mathrm{~m}, 50 \mathrm{~mm}$ provides enough detail (10 elements in the beam web height) with moderate computational cost. Figure 3 shows a typical connection in the global bridge model, with the typical element size highlighted.

Figure 3. General finite element mesh within connection region.

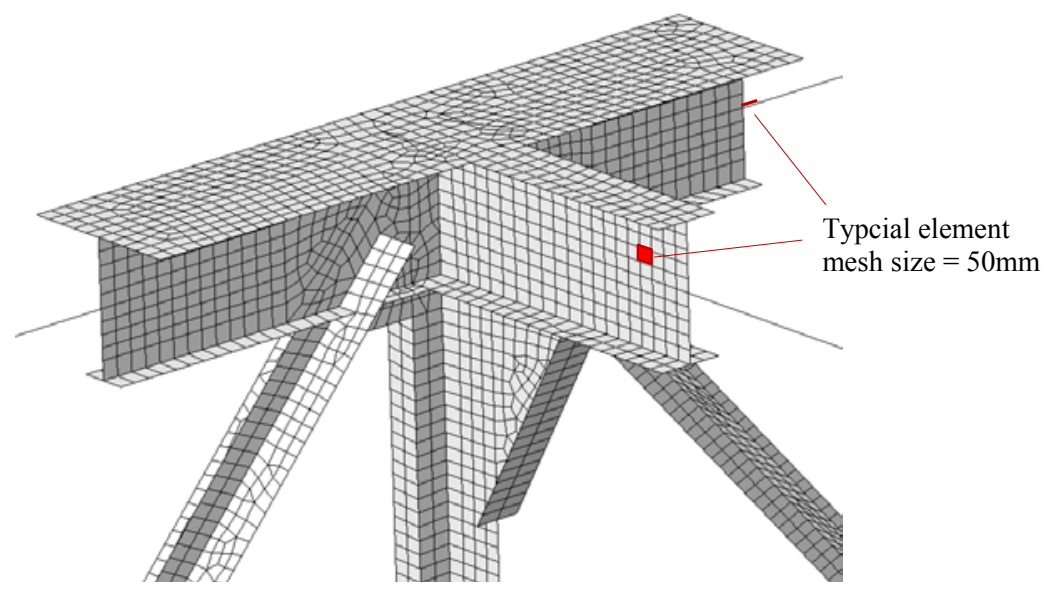


As explained earlier, beam elements are used outside the connection regions (where high stress concentrations are not expected) to further reduce computation effort. Figure 4 shows the compatibility between the shell and beam elements during analysis. All nodes on the shell element cross-section are rigidly tied to a reference node at the section centroid and beam elements are then connected to this reference node. Since the available degrees of freedom between the shell and beam elements are the same, no further constraints are required (this is not true for shell-to-solid or solid-to-beam elements). Note that the rigid ties to the reference node assume that "plane sections remain plane".

Figure 4. Shell-element to beam-element transition.

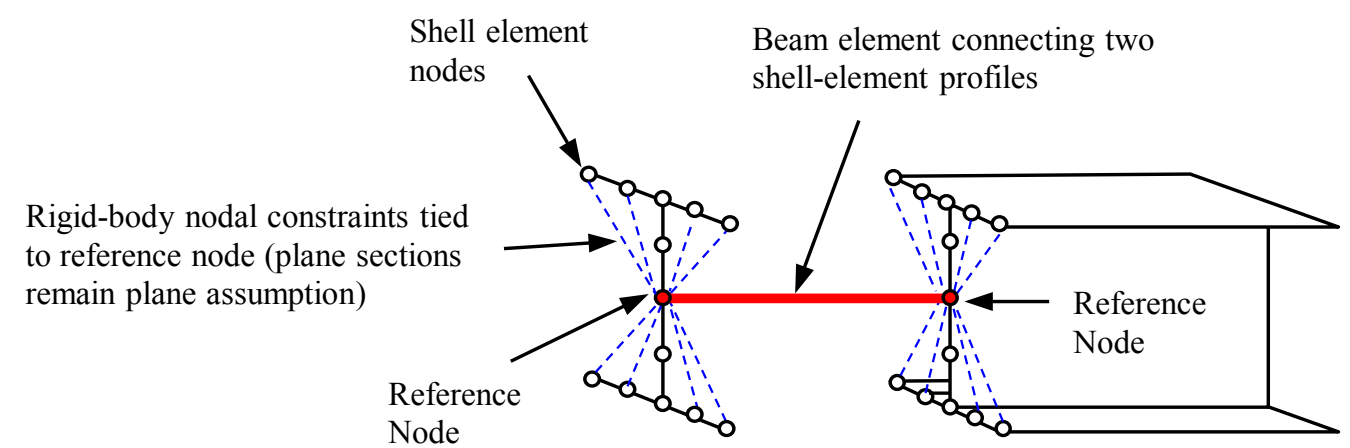

Global boundary conditions of the bridge model simulate the actual support condition of the constructed bridge. Construction documents indicate that the bridge is simply supported, with pin connections on one end and simple bearing rollers on the other (allowing longitudinal translation). Figure 5 shows the boundary conditions applied to the global model, with pinned supports on one end and longitudinal rollers on the other.

Figure 5. Bridge model support boundary conditions.

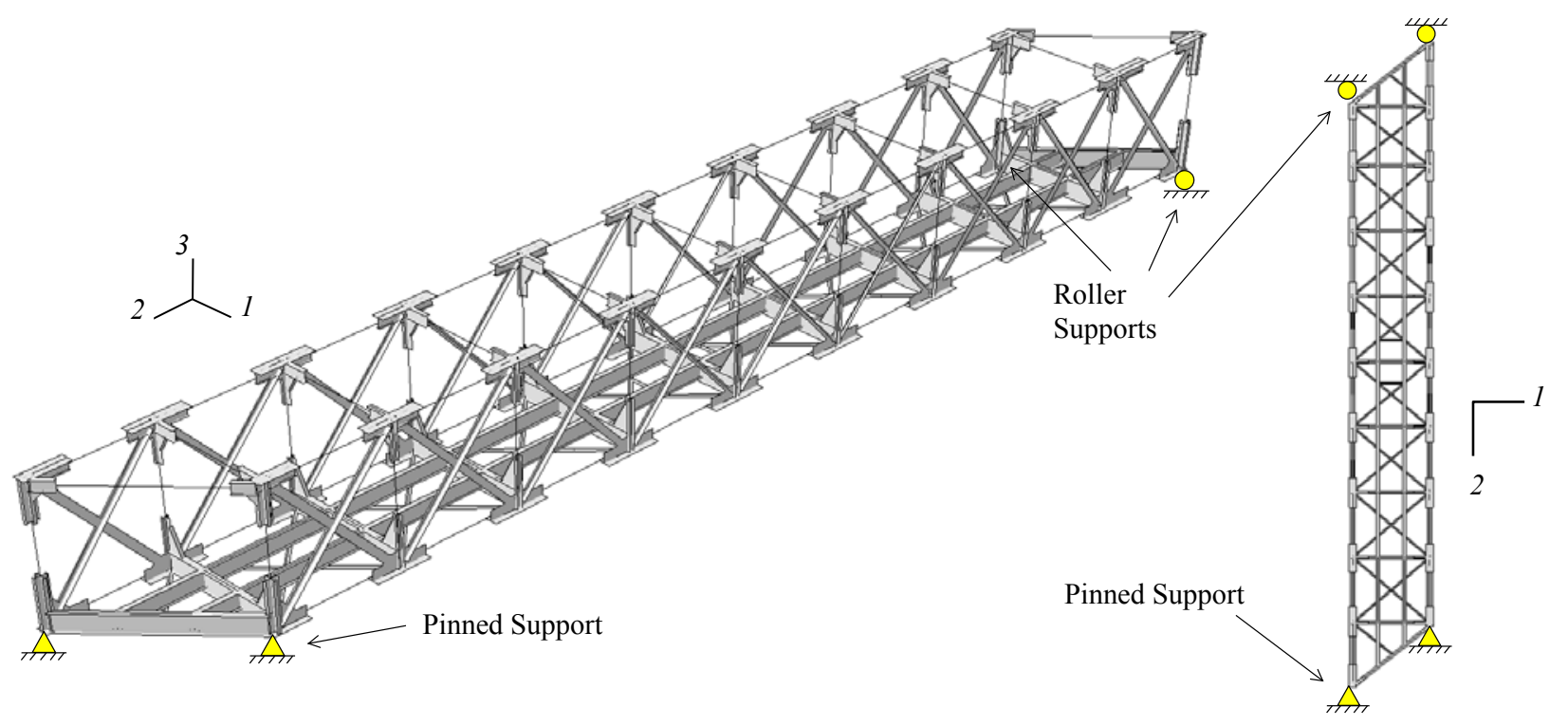

\subsubsection{Material Properties}

Because only service loads are applied to the bridge, only elastic material properties are used in the analysis. Elastic properties for steel are relatively consistent between steel grades (similar Young's 
modulus, $E$, and Poisson's ratio, v) eliminating the importance of knowing exactly what steel grade is present in the bridge. Typical steel values with an $E$ of $210,000 \mathrm{MPa}$ and $v$ of 0.3 were considered in the analysis. Pultruded CFRP plates, provided by the S\&P Clever Reinforcement Company in Switzerland, were used as strengthening elements. The pultrusion process is used to manufacture the plates. Young's modulus of $165,000 \mathrm{MPa}$ and ultimate strength of $2500 \mathrm{MPa}$ is assumed for the CFRP material. Fatigue life of composite materials are often assessed using piecewise constant life diagrams (CLD) (e.g., [3]). However, in general, the fatigue resistance of unidirectionally CFRP loaded in fibre direction is higher than that of steel, the reason why the fatigue in CFRP material is not discussed in this paper.

\subsubsection{Loading}

Sequences of dynamically applied loads simulate passage of train axles along the bridge length. Vertical loads corresponding to individual axle weights are activated and deactivated in series, at different time steps, simulating a moving line load. The process of activation and deactivation of the different loads are overlapped such that ramping-up of the following load occurs simultaneously with the ramping-down of the previous load. Figure 6 shows the train axle loading scheme, with the different axle loads overlapping during the time steps. Since all loads are applied dynamically at each time-step, inertial effects and vibrations from previous axle passages are included.

Figure 6. Train-axle loading scheme.

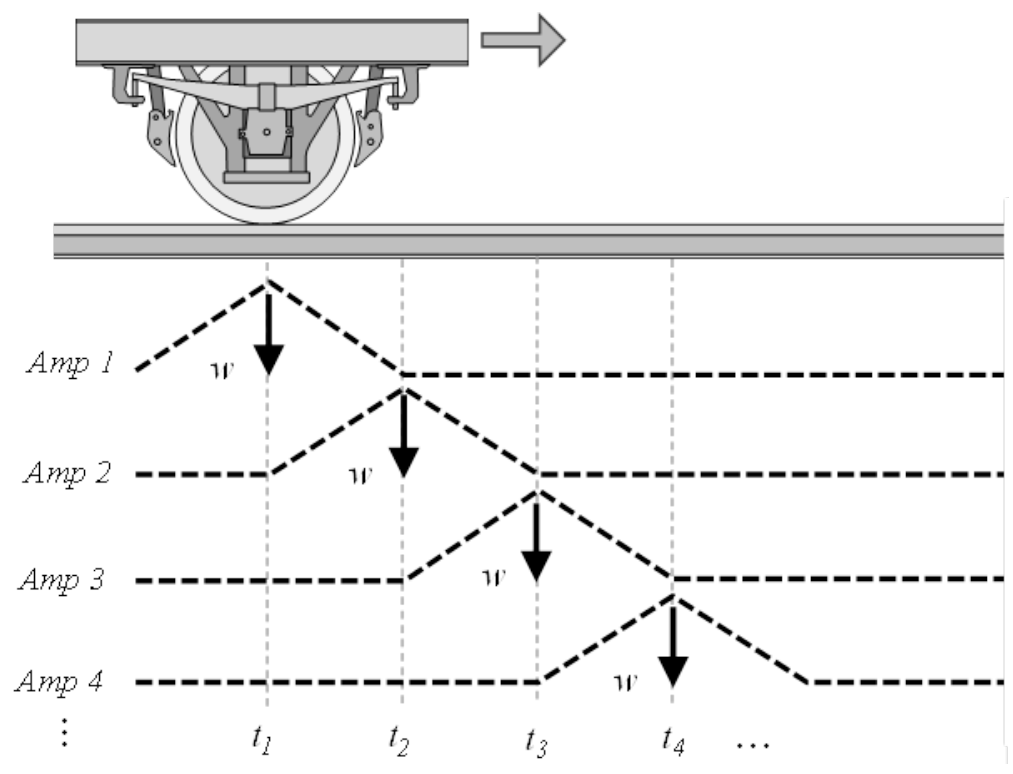

To determine fatigue critical locations and to allow relative comparison between the retrofit and non-retrofit situations, two different standard SBB trains are considered. Dead weight of the bridge is neglected as the loadings are only used for relative fatigue performance comparisons. Figure 7 shows the axle spacing and weights for two common passenger trains that cross the Münchenstein Bridge daily. Table 1 shows the total mass and axle load for each train with $0 \%$ and $100 \%$ passenger occupation assumptions. 
Figure 7. Load models of (a) S3 train; and (b) Intercity (ICN) train.

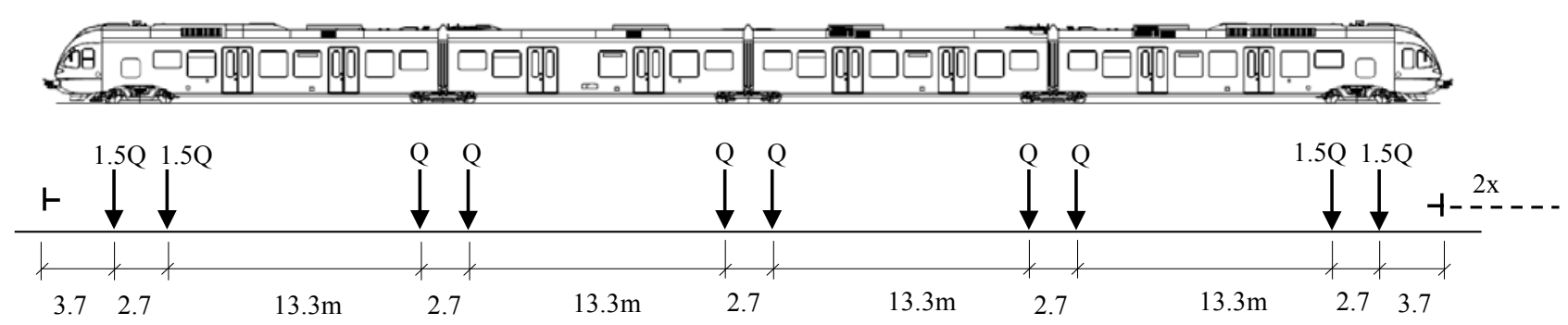

(a)

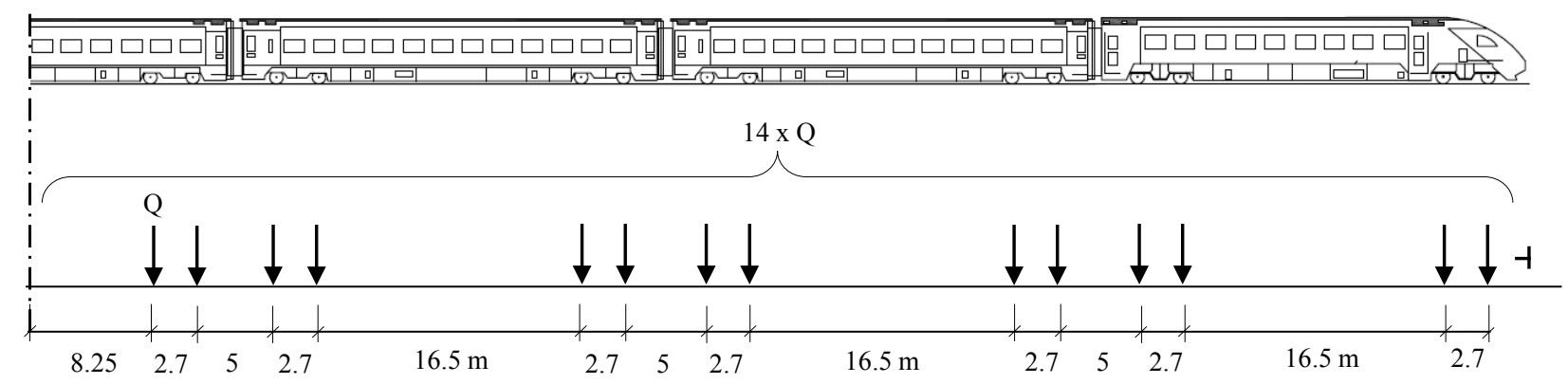

(b)

Table 1. Mass and axle load for each train with different passenger occupancy assumptions.

\begin{tabular}{cccc}
\hline S3 & Empty & Full & Unit \\
Total mass & 120 & 156.6 & Ton \\
Front axle load (1.5 Q) & 150 & 195.8 & $\mathrm{kN}$ \\
Rear axle load (Q) & 100 & 130.5 & $\mathrm{kN}$ \\
\hline ICN & Empty & Full & Unit \\
\hline Total mass & 359 & 421 & Ton \\
Axle load (Q) & 128 & 150 & $\mathrm{kN}$ \\
\hline
\end{tabular}

\subsubsection{Dynamic Modeling}

Sequences of dynamically applied loads as described before are used in order to take into account the dynamic behavior of the bridge due to the inertia and vibration produced by the previous axles. Rayleigh damping was used to consider the effects of damping on the bridge. The overall damping matrix can be obtained from the overall stiffness and mass matrices by

$$
[C]=\alpha[M]+\beta[K]
$$

where $\alpha$ and $\beta$ are constants. Orthogonality of the mode shapes results in [4];

$$
2 \zeta_{i} \omega_{i}=\alpha+\beta \omega_{i}^{2}
$$

which when given two independent modes, allows for the solution of $\alpha$ and $\beta$ as (see Equation (3))

$$
\alpha=\frac{2 \omega_{i} \omega_{j}\left(\zeta_{i} \omega_{j}-\zeta_{j} \omega_{i}\right)}{\omega_{j}^{2}-\omega_{i}^{2}}, \beta=\frac{2\left(\zeta_{j} \omega_{j}-\zeta_{i} \omega_{i}\right)}{\omega_{j}^{2}-\omega_{i}^{2}}
$$

In Equation (3), the damping ratio $\zeta_{i}$ and $\zeta_{j}$ correspond to any two natural frequencies of the structure $\omega_{i}$ and $\omega_{j}$, respectively. In this study, $2 \%$ damping is applied to the first and third bridge 
vibration modes [5,6]. Frequency analysis indicates the first and the second vibration frequencies as $\omega_{1}=17.54 \mathrm{rad} / \mathrm{s}$ and $\omega_{3}=31.37 \mathrm{rad} / \mathrm{s}$ resulting in $\alpha=0.45$ and $\beta=0.00082$ from Equation (3).

\subsubsection{CFRP Post-Tensioning}

Linear springs and connector elements simulate the CFRP post-tensioning system (see Figure 8). Linear springs with applied pre-stress simulate the CFRP plate stiffness; rigid nodal constraints simulate the plate attachment to the bridge cross-beam bottom flange; and rigid connector elements provide the eccentricity between the CFRP plate and beam bottom flange $(200 \mathrm{~mm}$ assumed in this study). The spring pre-stress is applied by translating the material constitutive behavior, which normally has zero stress at zero displacement, until the desired pre-stress level occurs at zero displacement (see Figure 8, and note that the CFRP plate stiffness is preserved). The retrofit system includes three CFRP plates each having dimensions of $50 \mathrm{~mm} \times 1.2 \mathrm{~mm}$ (entirely $180 \mathrm{~mm}^{2}$ ). Results from the global and local models with and without the CFRP post-tensioning retrofit are presented later in the Fatigue Analysis Section. The pre-stressed un-bonded system consists of two friction clamps, as shown in Figure 8b. It was tested in the laboratory and could survive more than 33,000,000 cycles. More results about the strengthening system will be published in another paper.

Figure 8. (a) Modeling of the un-bonded CFRP post-tensioning system; and (b) Scheme of the un-bonded CFRP post-tensioning system.

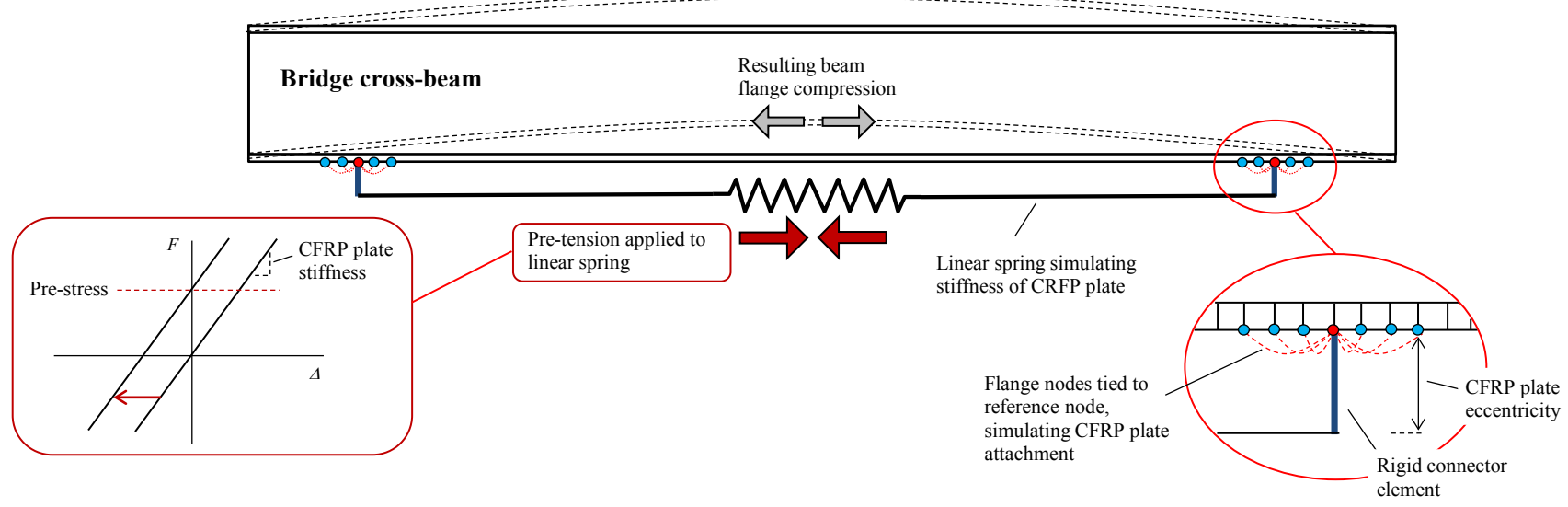

(a)

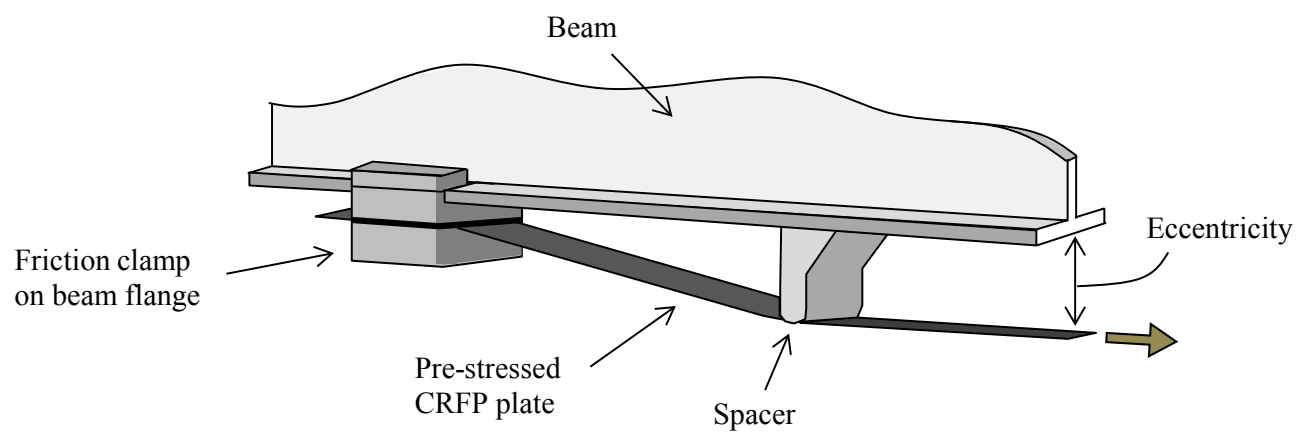

(b) 


\subsection{Riveted Joint Sub-Model}

The following sections involve related works concerning the establishment and analysis of local riveted joint sub-models. Based on the global model, a detailed sub-model of a riveted joint at the bottom flange of the cross-beam at the middle of the bridge is developed. The detailed sub-model is used to provide better understanding about stress distribution in regions near the rivet connections.

\subsubsection{Geometry, Element Type, and Rivet Interaction}

Individual riveted joint components (flange angles, web plates, and rivets) based on detailed construction drawings, are modeled using solid elements. The riveted joint sub-model is placed at the mid-span of the cross-beam in the middle of the bridge, as shown in Figure 9. Also shown in Figure 9 is the riveted sub-model joint geometry with individual components. The use of solid elements provides more accurate stress distributions through the thickness of each element and allows the determination of bearing stresses at the rivet hole edges.

Assembly of the sub-model components considers contact interaction between the various angles, plates, and rivets. Load transfer through the connection is primarily achieved through the individual rivet contacts. A friction coefficient of 0.35 is used [7]. Each rivet has an applied pre-tension of $100 \mathrm{MPa}$, simulating the clamping force applied following rivet cooling. The value of $100 \mathrm{MPa}$ is set based on similar studies (e.g., [8]) and corresponds to typical values measured for pre-stressing of existing structures [9-11] which is a function of the length of the rivet shank.

Figure 9. Riveted joint sub-model geometry, location and element type.

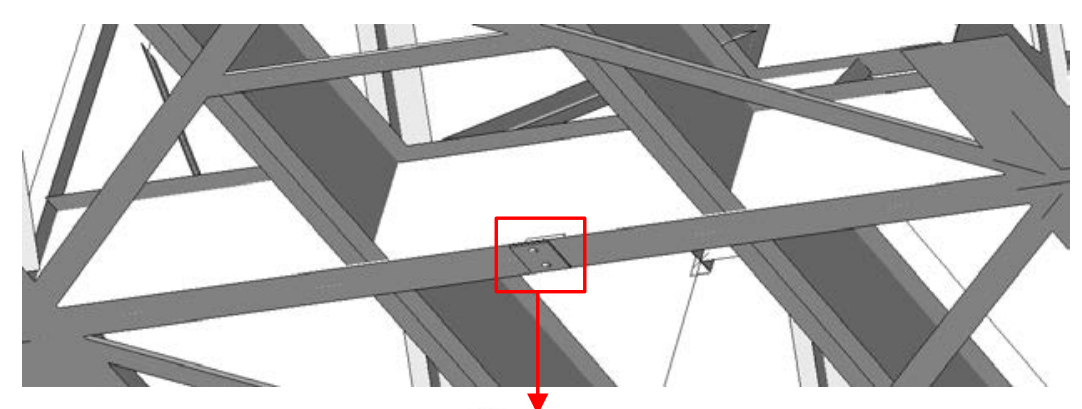

Individual steel sections to accurately simulate stress distribution

3-D Solid elements used for entire sub-model

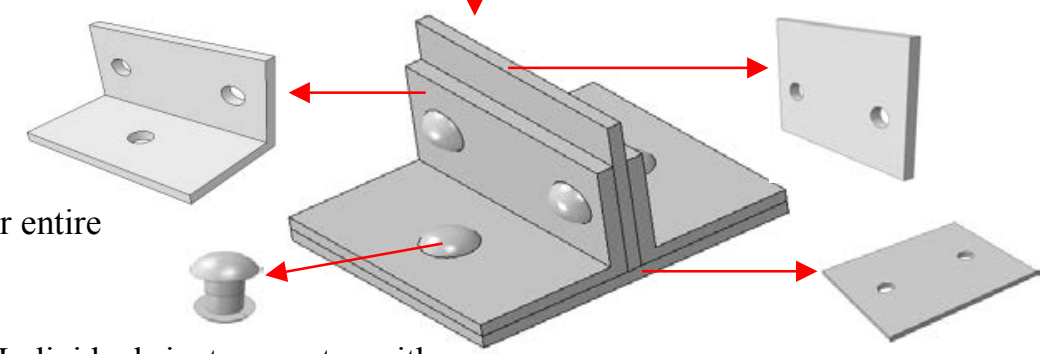

Individual rivet geometry with contact and pre-stress

\subsubsection{Mesh and Boundary Conditions}

Tetrahedral elements are used in the connection sub-model to simplify meshing of the complex three-dimensional geometry. Four-node tetrahedral elements at a general mesh size of $4 \mathrm{~mm}$ define the connection sub-model. For improved accuracy in critical regions, such as near the circular rivet holes, 
this general mesh size is reduced to near $2 \mathrm{~mm}$. Figure 10 shows an example meshed region including the riveted connections.

Figure 10. Joint sub-model mesh size and application of boundary conditions.

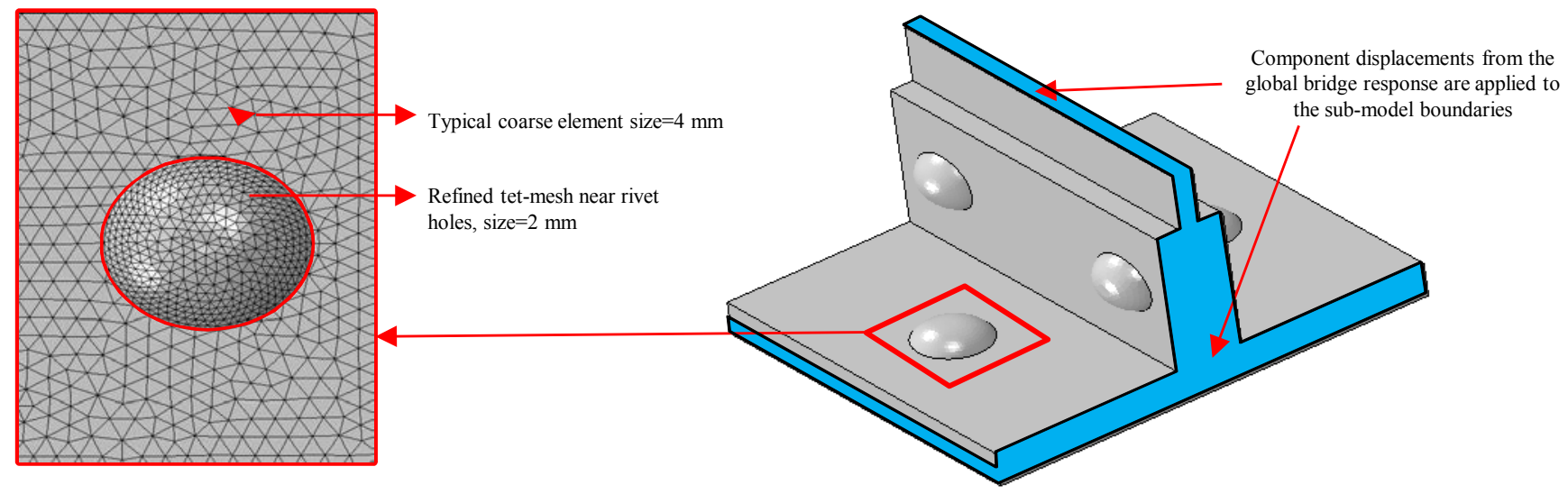

The connection sub-model is loaded through boundary conditions determined from the global bridge analysis. Since the available nodal degrees of freedom are different between shell and solid elements, boundary constraints apply nodal deformations to the solid-element sub-model based on (1) both displacements and rotations of the global shell-element nodes and (2) the location of the solid-element node relative to the shell center-line. All deformations and rotations from the global analysis are taken at locations corresponding to the cross-beam edge in the sub-model (highlighted by blue in Figure 10). Since the sub-model mesh is more refined than the global model, the displacements are interpolated to the nodes where there is no direct correspondence between the global model and sub-model.

\section{Verification of FE Model with Measurements}

In order to verify the accuracy of the global bridge model, strain measurements taken at different locations on the Münchenstein Bridge are compared with results of FE modeling. The measurements were conducted on the fourth cross-beam (from bridge mid-span), as shown in Figure 11a,b. Three magnetic strain gauges [12] were mounted on different locations near the cross-beam mid-span (see Figure 11b,c). Figure 12 shows the measured strain time-history at each position on the cross-beam for the ICN and S3 train passages. The ICN train has nearly the same axle load in each car, shown by similar strain peaks in Figure 12a. The S3 train has two units, the first and the last axle of each unit is heavier than the central axle load (see Figure 7a). With the S3 train (see Figure 12b), there are only 10 peaks in the deformation history for a total of 20 axles, due to close axle spacing $(2.7 \mathrm{~m})$ between train cars. With the ICN train (see Figure 12a), the distance between the centers of two consecutive axle groups is nearly $7.7(5+2.7) \mathrm{m}$, allowing the individual axle peaks to be measured. The results from the dynamic bridge model with different damping coefficient factors and levels of passenger occupations are compared in Figure 13. The three graphs on the left column show the variation of deformation as a function of damping coefficient for S3 load model with $0 \%$ passenger occupancy. All curves overlap substantially. Results show that damping has little influence on the amplitude of the deformations, however from the curves in the circled area in Figure 13, it can be found that the higher damping factor results in smoother curve. 
Figure 11. (a) Top view of the bridge indicating location of fourth cross-beam; (b) Cross-beam geometry; and the measurement plane (c) exact position of gauges and (d) three magnetic strain gauges.
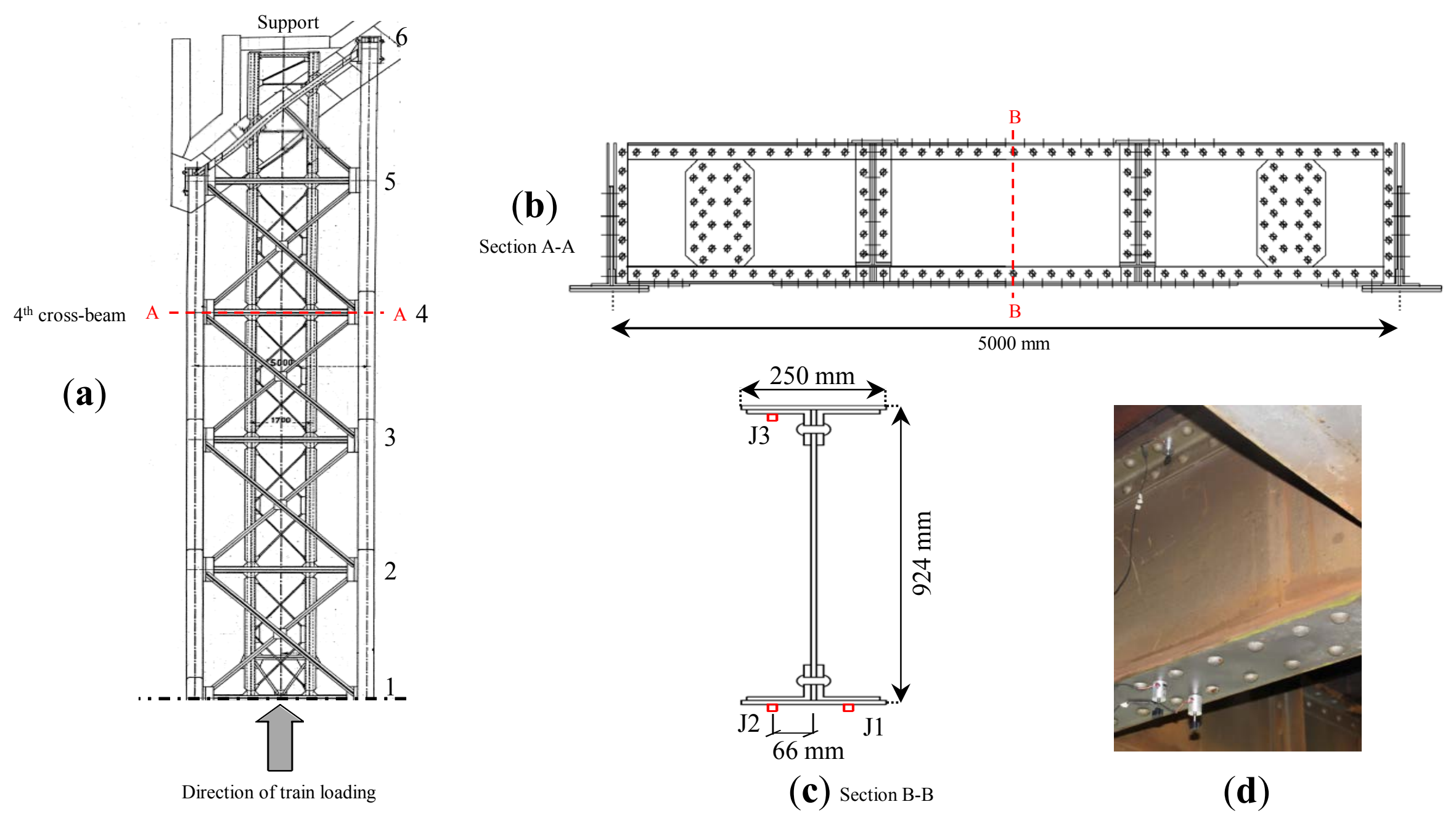
Figure 12. Strain measured at different locations of fourth cross-beam of Münchenstein Bridge while (a) ICN train; and (b) S3 train passes across the bridge.

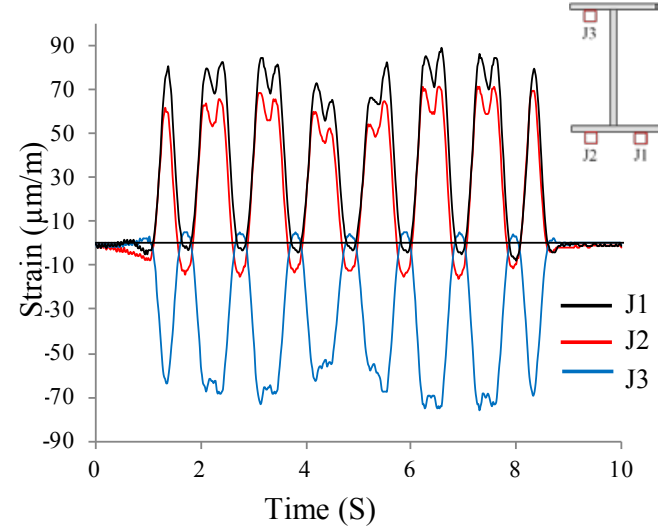

(a)

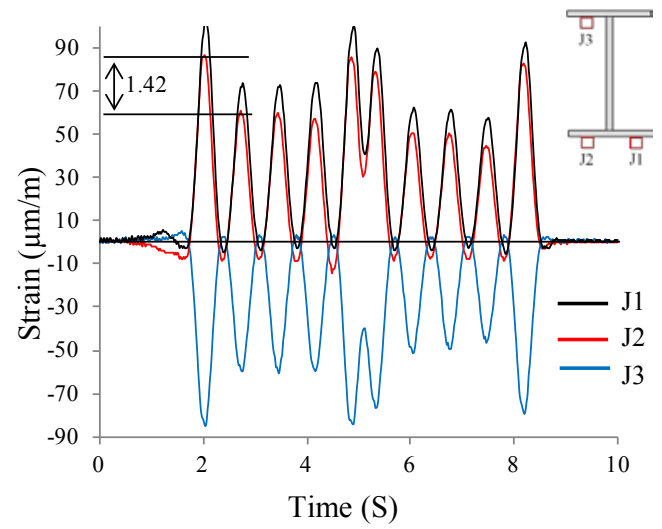

(b)

Figure 13. Comparison between measurements and FE results with different damping ratios and passenger occupancy levels.

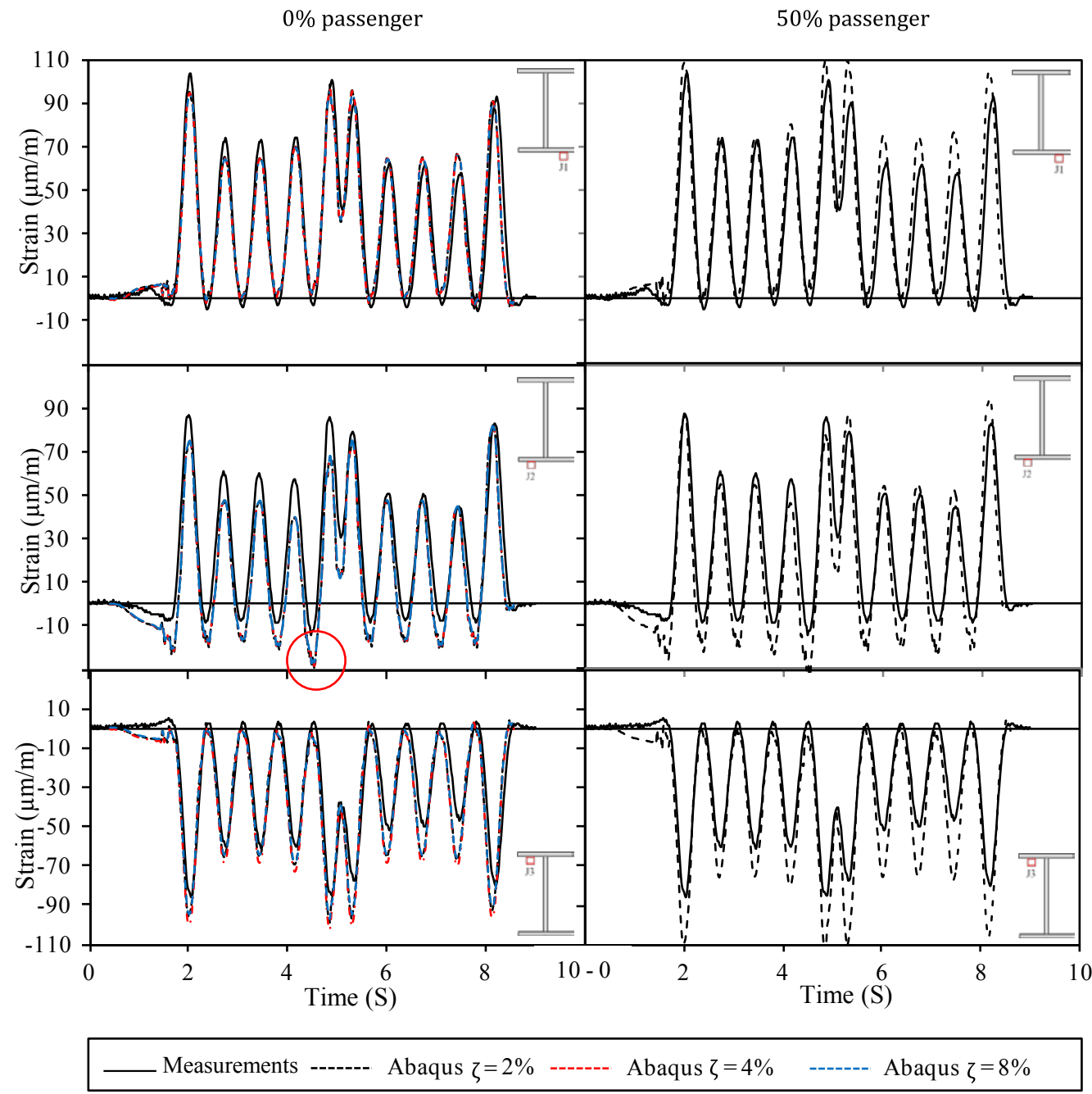

The graphs in the right column of Figure 13 show the effect of $50 \%$ passenger occupation when the damping coefficient is $2 \%$. The FE models have a generally good agreement with actual 
measurements. Some differences in the magnitude of peaks could be due to the unknown level of passenger occupancy in the train during measurements. Results from the sub-modeling of the riveted joint will be discussed later in Section 4.2.

\section{Fatigue Analysis Comparison}

\subsection{Global Model}

\subsubsection{Critical Regions and Stress Ranges on Existing Structure}

To determine the bridge locations critical for fatigue, stress cycles from different locations are determined and compared. Figure 14a shows the stress range values resulting in the cross-beam web near the longitudinal-to-cross-beam connections. Figure $14 \mathrm{~b}$ shows the stress range values resulting at the mid-span of the cross-beam bottom flange. Note in Figure 14b, that the cross-beams near the supports are subjected to out-of-plane bending resulting from deformation of the longitudinal beams (deformation induced stresses), the reason why stress ranges are shifted upward (in the tension region) as elements get closer to the supports.

Fatigue damage resulting from these different stress range values (see Figures 14a and 15b) is determined through cycle counting and linear fatigue damage accumulation models. Rainflow cycle counting and Miner's damage accumulation rule are used in this study. Using Miner's rule (see Equation (4)), damage is dependent on the fatigue capacity at each applied stress range (see Equation (5)), with higher stress range values leading to higher damage. Individual cycles, $n_{i}$, and stress range values, $\Delta \sigma$, are determined through a Rainflow cycle counting procedure.

$$
\begin{gathered}
\sum D_{i}=\sum\left(n_{i} / N_{i}\right) \\
N_{i}=C(\Delta \sigma)^{-m}
\end{gathered}
$$

In Equation (4), $D_{i}, n_{i}$, and $N_{i}$, are the damage, number of cycles, and number of cycles to failure, for each applied stress range, $i$. The number of cycles to failure in Equation (5) is based on the applied stress range $(\Delta \sigma)$ and $\mathrm{S}-\mathrm{N}$ curve parameters $(C$ and $m)$ where $C$ is $\Delta \sigma_{c}{ }^{m} \cdot 2,000,000[13,14]$.

Table 2 shows the damage in different details of the bridge due to the stress histories shown in Figure 14. Note from Table 2 that while the stress ranges and the corresponding damages levels are small (as should be expected from light passenger trains), the values still give a good relative indication of where the most fatigue prone detail is located. From Table 2, the highest damage in the longitudinal-to-cross-beam connection occurs at location 8 (i.e., in the fourth cross-beam from the bridge mid-span). The highest damage in the cross-beam bottom flange occurs at location 4 (i.e., fourth cross-beam from bridge mid-span). Comparing the two locations, it is seen that the fourth cross-beam is the most critical (fastest at accumulating damage) location among all other cross-beam bottom flanges and longitudinal-to-cross-beam connections. Note that the aim of the method presented in this paper is to compare accumulated damage at different critical locations of the bridge due to one train passage and find out how strengthening reduces the fatigue damage. However, if the method is intended to be used for design or fatigue verification of a metallic bridge, the constant amplitude fatigue threshold (CAFT) shall be considered in the analysis too. 
Figure 14. Stress range due to ICN train load model at (a) Longitudinal-to-cross girders (longitudinal stress, $\sigma_{y y}$ ); and (b) Cross-beams at mid-span (longitudinal stress, $\sigma_{y y}$ ).

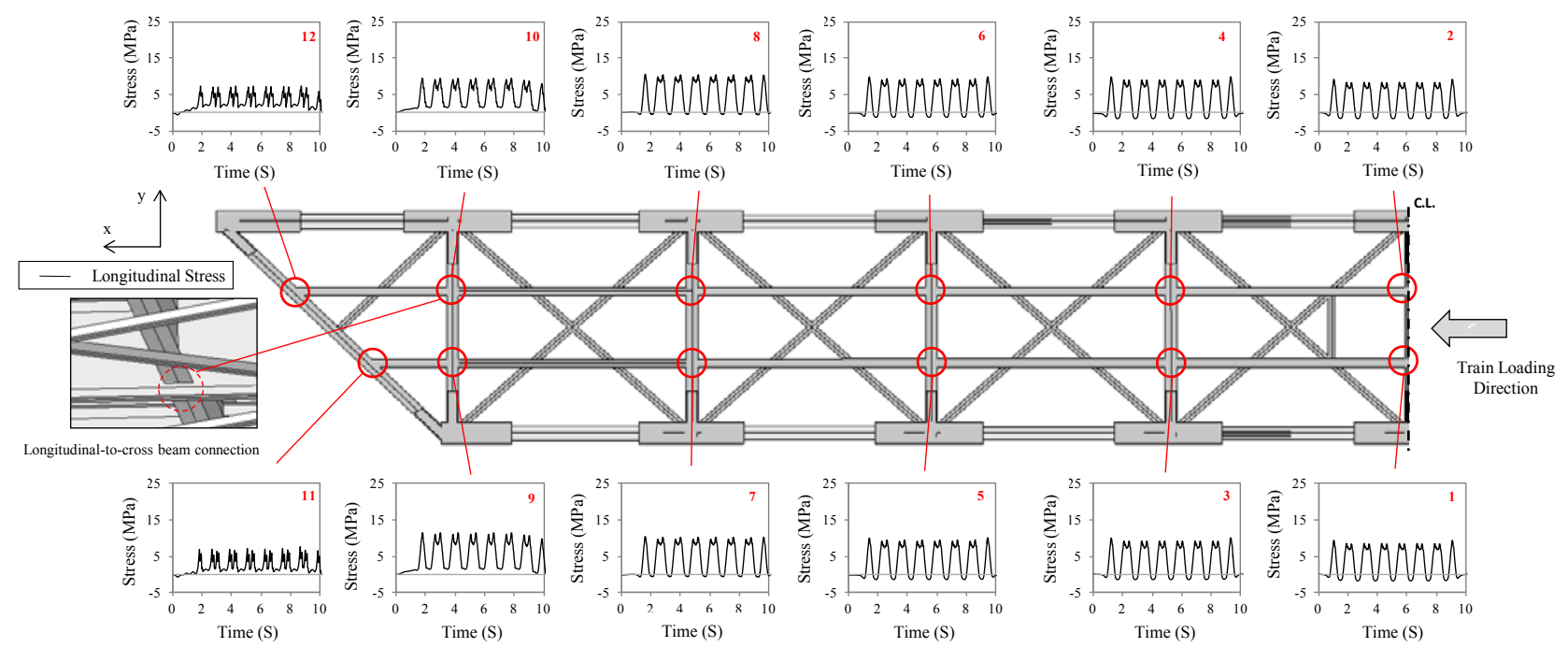

(a)

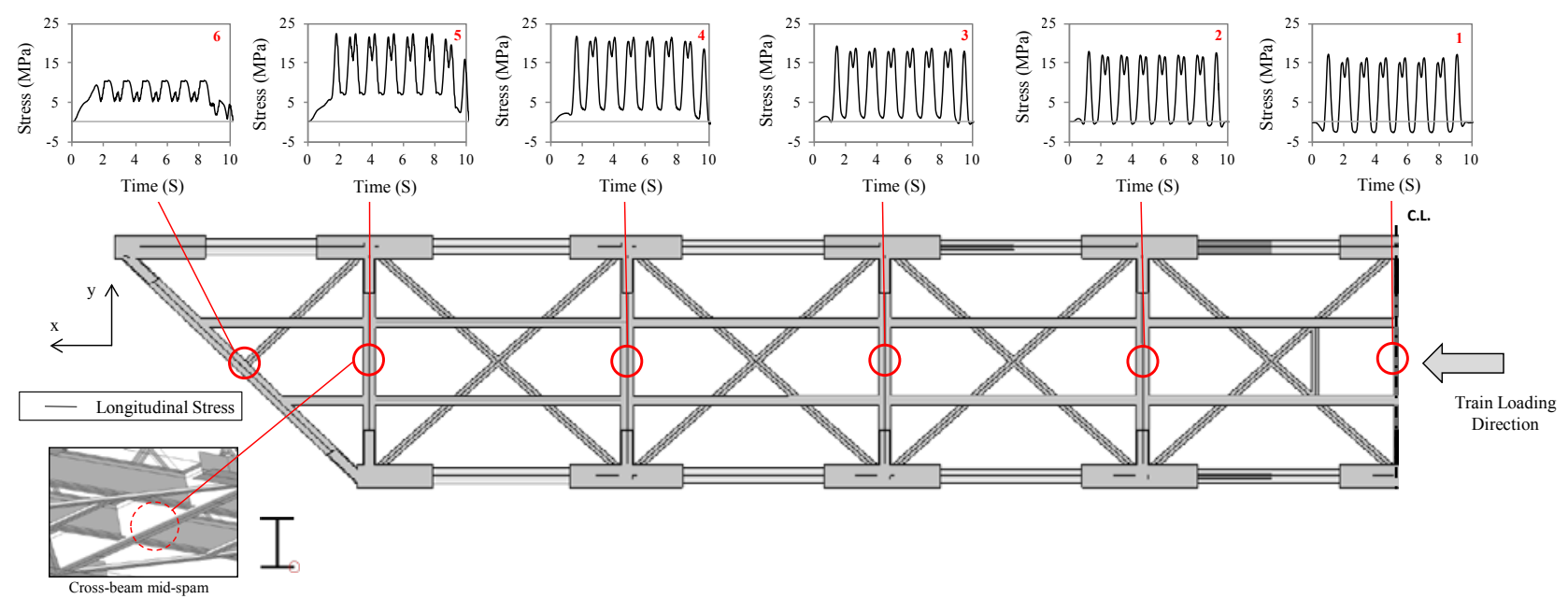

(b) 
Table 2. Fatigue damage calculation for (a) cross-beam bottom flange locations and (b) Longitudinal-to-cross-beam connection locations due to passage of one ICN train load model.

(a)

\begin{tabular}{|c|c|c|c|c|c|}
\hline \multirow{2}{*}{ Position $^{\text {a }}$} & \multicolumn{2}{|c|}{$\Delta \sigma\left[\right.$ Mpa]Number of Cycles $\left[n_{i}\right]$} & \multirow{2}{*}{$\frac{\boldsymbol{N}_{\boldsymbol{i}}^{\mathbf{b}}}{2.91 \times 10^{9}}$} & \multicolumn{2}{|c|}{ Damage $\left[D_{i}\right]$ Total Damage $\left[\sum D_{i}\right]$} \\
\hline & 18.6 & 1 & & $3.43 \times 10^{-10}$ & \multirow{4}{*}{$2.24 \times 10^{-9}$} \\
\hline \multirow{3}{*}{1} & 18.2 & 1 & $3.30 \times 10^{9}$ & $3.03 \times 10^{-10}$ & \\
\hline & 17.7 & 5 & $3.73 \times 10^{9}$ & $1.34 \times 10^{-9}$ & \\
\hline & 17.6 & 1 & $3.88 \times 10^{9}$ & $2.58 \times 10^{-10}$ & \\
\hline \multirow{6}{*}{2} & 3.7 & 6 & $9.45 \times 10^{12}$ & $6.35 \times 10^{-13}$ & \multirow{6}{*}{$2.27 \times 10^{-9}$} \\
\hline & 19.2 & 1 & $2.50 \times 10^{9}$ & $4.00 \times 10^{-10}$ & \\
\hline & 18.6 & 1 & $2.94 \times 10^{9}$ & $3.41 \times 10^{-10}$ & \\
\hline & 17.6 & 2 & $3.93 \times 10^{9}$ & $5.09 \times 10^{-10}$ & \\
\hline & 17.5 & 4 & $3.94 \times 10^{9}$ & $1.02 \times 10^{-9}$ & \\
\hline & 4.5 & 6 & $3.40 \times 10^{12}$ & $2.77 \times 10^{-12}$ & \\
\hline \multirow{5}{*}{3} & 19.9 & 1 & $2.09 \times 10^{9}$ & $4.78 \times 10^{-10}$ & \multirow{5}{*}{$2.43 \times 10^{-9}$} \\
\hline & 18.4 & 1 & $3.10 \times 10^{9}$ & $3.23 \times 10^{-10}$ & \\
\hline & 17.8 & 5 & $3.65 \times 10^{9}$ & $1.37 \times 10^{-9}$ & \\
\hline & 17.7 & 1 & $3.80 \times 10^{9}$ & $2.63 \times 10^{-10}$ & \\
\hline & 4.1 & 6 & $5.74 \times 10^{12}$ & $1.04 \times 10^{-12}$ & \\
\hline \multirow{7}{*}{4} & 22.4 & 1 & $1.17 \times 10^{9}$ & $8.58 \times 10^{-10}$ & \multirow{7}{*}{$3.08 \times 10^{-9}$} \\
\hline & 18.6 & 3 & $2.92 \times 10^{9}$ & $1.03 \times 10^{-9}$ & \\
\hline & 18.5 & 2 & $2.99 \times 10^{9}$ & $6.70 \times 10^{-10}$ & \\
\hline & 17.8 & 1 & $3.64 \times 10^{9}$ & $2.74 \times 10^{-10}$ & \\
\hline & 17.5 & 1 & $3.99 \times 10^{9}$ & $2.51 \times 10^{-10}$ & \\
\hline & 4.2 & 1 & $5.09 \times 10^{12}$ & $2.96 \times 10^{-13}$ & \\
\hline & 3.9 & 5 & $6.88 \times 10^{12}$ & $27.27 \times 10^{-13}$ & \\
\hline \multirow{5}{*}{5} & 22.5 & 1 & $1.14 \times 10^{9}$ & $8.75 \times 10^{-10}$ & \multirow{5}{*}{$1.76 \times 10^{-9}$} \\
\hline & 15.6 & 5 & $7.00 \times 10^{9}$ & $7.14 \times 10^{-10}$ & \\
\hline & 14.2 & 1 & $1.13 \times 10^{10}$ & $8.86 \times 10^{-11}$ & \\
\hline & 13.6 & 1 & $1.39 \times 10^{10}$ & $7.21 \times 10^{-11}$ & \\
\hline & 6.0 & 6 & $8.43 \times 10^{11}$ & $7.12 \times 10^{-12}$ & \\
\hline \multirow{5}{*}{6} & 10.5 & 1 & $5.18 \times 10^{10}$ & $1.93 \times 10^{-11}$ & \multirow{5}{*}{$2.34 \times 10^{-11}$} \\
\hline & 5.4 & 5 & $1.38 \times 10^{12}$ & $23.63 \times 10^{-12}$ & \\
\hline & 4.2 & 1 & $4.85 \times 10^{12}$ & $2.06 \times 10^{-13}$ & \\
\hline & 3.8 & 2 & $8.53 \times 10^{12}$ & $2.34 \times 10^{-13}$ & \\
\hline & 2.4 & 5 & $8.23 \times 10^{13}$ & $6.08 \times 10^{-14}$ & \\
\hline
\end{tabular}

Notes: ${ }^{\text {a }}$ See Figure $14 \mathrm{~b} ;{ }^{\mathrm{b}} \mathrm{C}=6.55 \times 10^{15}$ and $m=5$, from S-N curves for riveted structures with detail category 80 [13]. The differences in stress $(\Delta \sigma)$ are calculated by taking into account $60 \%$ of the portion of the compression cycle [14]. 
(b)

\begin{tabular}{|c|c|c|c|c|c|}
\hline Position ${ }^{\text {a }}$ & $\Delta \sigma[$ Mpa] & Number of Cycles $\left[n_{i}\right]$ & $N_{i}{ }^{\mathbf{b}}$ & Damage $\left[D_{i}\right]$ & Total Damage $\left[\sum D_{i}\right]$ \\
\hline \multirow{3}{*}{1} & 10.3 & 1 & $3.04 \times 10^{10}$ & $3.29 \times 10^{-11}$ & \multirow{3}{*}{$1.83 \times 10^{-10}$} \\
\hline & 9.5 & 5 & $4.56 \times 10^{10}$ & $1.10 \times 10^{-10}$ & \\
\hline & 9.4 & 2 & $5.00 \times 10^{10}$ & $4.00 \times 10^{-11}$ & \\
\hline \multirow{3}{*}{2} & 10.3 & 1 & $3.05 \times 10^{10}$ & $3.28 \times 10^{-11}$ & \multirow{3}{*}{$1.85 \times 10^{-10}$} \\
\hline & 9.6 & 1 & $4.37 \times 10^{10}$ & $2.29 \times 10^{-11}$ & \\
\hline & 9.5 & 6 & $4.65 \times 10^{10}$ & $1.29 \times 10^{-10}$ & \\
\hline \multirow{3}{*}{3} & 10.9 & 1 & $2.37 \times 10^{10}$ & $4.21 \times 10^{-11}$ & \multirow{3}{*}{$2.38 \times 10^{-10}$} \\
\hline & 10.2 & 1 & $3.22 \times 10^{10}$ & $3.11 \times 10^{-11}$ & \\
\hline & 10.0 & 6 & $3.63 \times 10^{10}$ & $1.65 \times 10^{-10}$ & \\
\hline \multirow{3}{*}{4} & 10.8 & 1 & $2.46 \times 10^{10}$ & $4.07 \times 10^{-11}$ & \multirow{3}{*}{$2.34 \times 10^{-10}$} \\
\hline & 10.2 & 1 & $3.22 \times 10^{10}$ & $3.11 \times 10^{-11}$ & \\
\hline & 9.9 & 6 & $3.70 \times 10^{10}$ & $1.62 \times 10^{-10}$ & \\
\hline \multirow{3}{*}{5} & 10.7 & 1 & $2.52 \times 10^{10}$ & $3.96 \times 10^{-11}$ & \multirow{3}{*}{$2.51 \times 10^{-10}$} \\
\hline & 10.4 & 1 & $3.02 \times 10^{10}$ & $3.32 \times 10^{-11}$ & \\
\hline & 10.1 & 6 & $3.36 \times 10^{10}$ & $1.78 \times 10^{-10}$ & \\
\hline \multirow{3}{*}{6} & 10.8 & 1 & $2.50 \times 10^{10}$ & $4.01 \times 10^{-11}$ & \multirow{3}{*}{$2.61 \times 10^{-10}$} \\
\hline & 10.4 & 1 & $2.90 \times 10^{10}$ & $3.45 \times 10^{-11}$ & \\
\hline & 10.2 & 6 & $3.21 \times 10^{10}$ & $1.87 \times 10^{-10}$ & \\
\hline \multirow{3}{*}{7} & 10.8 & 1 & $2.47 \times 10^{10}$ & $4.04 \times 10^{-11}$ & \multirow{3}{*}{$2.84 \times 10^{-10}$} \\
\hline & 10.5 & 2 & $2.81 \times 10^{10}$ & $7.12 \times 10^{-11}$ & \\
\hline & 10.4 & 5 & $2.90 \times 10^{10}$ & $1.72 \times 10^{-10}$ & \\
\hline \multirow{4}{*}{8} & 10.9 & 1 & $2.37 \times 10^{10}$ & $4.22 \times 10^{-11}$ & \multirow{4}{*}{$3.03 \times 10^{-10}$} \\
\hline & 10.7 & 1 & $2.63 \times 10^{10}$ & $3.81 \times 10^{-11}$ & \\
\hline & 10.6 & 4 & $2.65 \times 10^{10}$ & $1.51 \times 10^{-10}$ & \\
\hline & 10.5 & 2 & $2.79 \times 10^{10}$ & $7.16 \times 10^{-11}$ & \\
\hline \multirow{4}{*}{9} & 11.6 & 1 & $1.73 \times 10^{10}$ & $5.78 \times 10^{-11}$ & \multirow{4}{*}{$2.49 \times 10^{-10}$} \\
\hline & 10.1 & 5 & $3.40 \times 10^{10}$ & $1.47 \times 10^{-10}$ & \\
\hline & 9.6 & 2 & $4.49 \times 10^{10}$ & $4.45 \times 10^{-11}$ & \\
\hline & 3.1 & 1 & $1.34 \times 10^{10}$ & $7.46 \times 10^{-14}$ & \\
\hline \multirow{4}{*}{10} & 9.7 & 1 & $4.29 \times 10^{10}$ & $2.33 \times 10^{-11}$ & \multirow{4}{*}{$9.47 \times 10^{-11}$} \\
\hline & 8.3 & 5 & $9.00 \times 10^{10}$ & $5.56 \times 10^{-11}$ & \\
\hline & 7.7 & 2 & $1.30 \times 10^{11}$ & $1.53 \times 10^{-11}$ & \\
\hline & 3.1 & 6 & $1.24 \times 10^{13}$ & $4.82 \times 10^{-13}$ & \\
\hline \multirow{6}{*}{11} & 8.2 & 1 & $9.73 \times 10^{10}$ & $1.03 \times 10^{-11}$ & \multirow{6}{*}{$3.00 \times 10^{-11}$} \\
\hline & 6.3 & 2 & $3.64 \times 10^{11}$ & $5.50 \times 10^{-12}$ & \\
\hline & 6.1 & 2 & $4.27 \times 10^{11}$ & $4.68 \times 10^{-12}$ & \\
\hline & 6.0 & 2 & $4.64 \times 10^{11}$ & $4.31 \times 10^{-12}$ & \\
\hline & 5.1 & 4 & $1.05 \times 10^{12}$ & $3.82 \times 10^{-12}$ & \\
\hline & 4.8 & 2 & $1.42 \times 10^{12}$ & $1.41 \times 10^{-12}$ & \\
\hline \multirow{5}{*}{12} & 8.0 & 1 & $1.10 \times 10^{11}$ & $9.08 \times 10^{-12}$ & \multirow{5}{*}{$3.03 \times 10^{-11}$} \\
\hline & 6.0 & 3 & $4.64 \times 10^{11}$ & $6.46 \times 10^{-12}$ & \\
\hline & 5.7 & 2 & $6.00 \times 10^{11}$ & $3.33 \times 10^{-12}$ & \\
\hline & 5.6 & 2 & $6.55 \times 10^{11}$ & $3.05 \times 10^{-12}$ & \\
\hline & 5.5 & 6 & $7.17 \times 10^{11}$ & $8.37 \times 10^{-12}$ & \\
\hline
\end{tabular}

Notes: ${ }^{\text {a }}$ See Figure $14 \mathrm{a} ;{ }^{\mathrm{b}} \mathrm{C}=3.6 \times 10^{15}$ and $m=5$, from S-N curves for riveted structures with detail category 71 [13]. 


\subsubsection{Effect of CFRP Post-Tensioning on Fatigue Susceptibility}

Based on the global model fatigue results, the effects of the CFRP retrofit are investigated for all six cross-beam bottom flanges (see Figure 14b) and 12 longitudinal-to-cross beam connections (see Figure 14a). Two different levels of pre-stress $20 \%$ and $40 \%\left(\sigma_{\mathrm{u}} \mathrm{CFRP}\right)$ are considered for each detail. Figure 15a,b show the resulting stress-range values at the first cross-beam bottom flange (see Figure 14b) and the first longitudinal-to-cross beam connection (Figure 14a), respectively, for each level of CFRP pre-stress. From Figure 15, with increased CFRP pre-stress, a rigid shift in stress range history occurs, lowering the mean stress while the compressive-to-tensile stress ranges remain similar to the un-retrofitted case. Table 3 shows the resulting fatigue damage at each location for each level of pre-stress. With the non-welded details, $40 \%$ of the compressive stress ranges are neglected (i.e., $60 \%$ is taken into account) [14], causing the rigid shift in mean stress to have a great effect on damage reduction. With an applied $40 \%$ CFRP pre-stress, more than $87 \%$ and $85 \%$ reductions in fatigue damage are calculated at longitudinal-to-cross beam connections and cross-beam bottom flanges, respectively. With $20 \%\left(\sigma_{u}\right.$ CFRP) pre-stress the damage reduction is lower for the longitudinal-to-cross beam connections compared to cross-beam bottom flanges (more than $45 \%$ reduction versus more than $60 \%$ reduction, respectively). This is because the CFRP retrofit has lower influence on fatigue at the longitudinal-to-cross beam connection due to the influence of the deformation induced stresses from the longitudinal bridge members, which are not affected by the cross-beam CFRP retrofit.

Figure 15. Stress ranges at (a) the first cross-beam bottom flange (see Figure 14b); and (b) The first longitudinal-to-cross beam connection (see Figure 14a), for different CFRP pre-stresses.

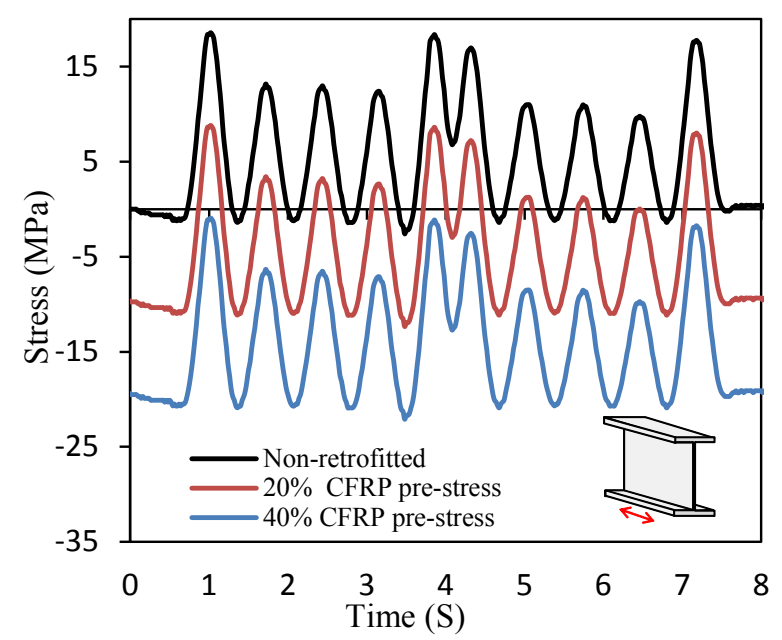

(a)

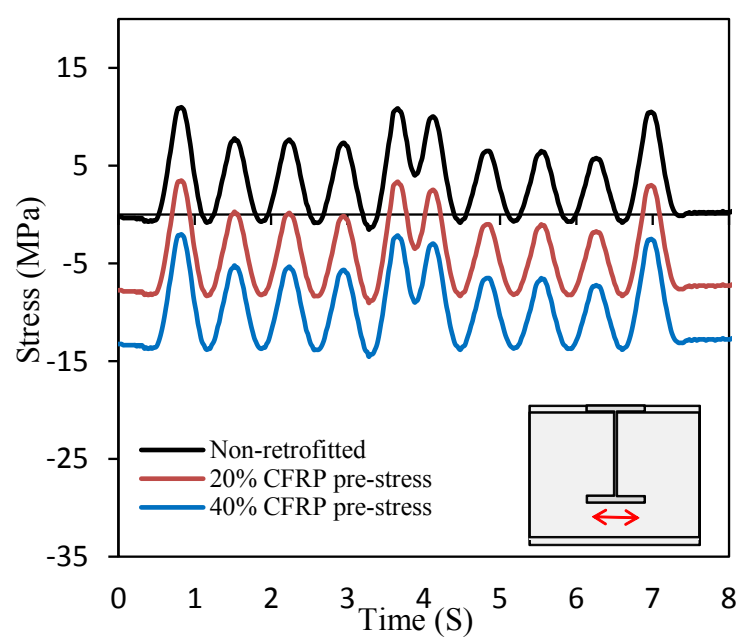

(b) 
Table 3. Fatigue damage reduction at different CFRP pre-stress levels due to S3 train passage for (a) cross-beam bottom flange locations and (b) longitudinal-to-cross-beam connection locations.

(a)

\begin{tabular}{cccc}
\hline Location $^{\mathbf{a}}$ Non-Retrofitted & ${ }^{\mathbf{b}}$ Damage Reduction by 20\% Pre-Stress \\
\hline & $\mathbf{c}$ & Damage Reduction by 40\% Pre-Stress & $\mathbf{c}$ \\
2 & $2.75 \times 10^{-9}$ & $66.74 \%$ & $91.07 \%$ \\
3 & $2.93 \times 10^{-9}$ & $66.95 \%$ & $91.57 \%$ \\
4 & $3.08 \times 10^{-9}$ & $67.08 \%$ & $92.22 \%$ \\
5 & $3.46 \times 10^{-9}$ & $60.20 \%$ & $88.71 \%$ \\
6 & $1.97 \times 10^{-9}$ & $60.42 \%$ & $85.10 \%$ \\
\hline
\end{tabular}

Notes: ${ }^{\text {a }}$ See Figure $14 \mathrm{~b} ;{ }^{\mathrm{b}} \mathrm{C}=6.55 \times 10^{15}$ and $m=5$, from S-N curves for riveted structures with detail category $80 ;{ }^{\mathrm{c}}$ Fatigue damage reduction from non-retrofitted case.

(b)

\begin{tabular}{|c|c|c|c|}
\hline \multicolumn{4}{|c|}{ Location ${ }^{\mathrm{a}}$ Non-Retrofitted ${ }^{\mathrm{b}}$ Damage Reduction by $20 \%$ Pre-Stress ${ }^{\mathrm{c}}$ Damage Reduction by $40 \%$ Pre-Stress ${ }^{\mathrm{c}}$} \\
\hline 1 & $2.88 \times 10^{-10}$ & 50.44 & $87.09 \%$ \\
\hline 2 & $2.93 \times 10^{-10}$ & 50.37 & $87.15 \%$ \\
\hline 3 & $3.92 \times 10^{-10}$ & 48.96 & $88.22 \%$ \\
\hline 4 & $3.89 \times 10^{-10}$ & 48.87 & $88.27 \%$ \\
\hline 5 & $3.80 \times 10^{-10}$ & 47.93 & $90.08 \%$ \\
\hline 6 & $3.78 \times 10^{-10}$ & 48.03 & $90.11 \%$ \\
\hline 7 & $3.39 \times 10^{-10}$ & 47.09 & $92.04 \%$ \\
\hline 8 & $3.57 \times 10^{-10}$ & 47.45 & $92.03 \%$ \\
\hline 9 & $2.45 \times 10^{-10}$ & 46.78 & $92.2 \%$ \\
\hline 10 & $9.39 \times 10^{-11}$ & 46.86 & $92.2 \%$ \\
\hline 11 & $3.28 \times 10^{-11}$ & 45.45 & $92.2 \%$ \\
\hline 12 & $3.54 \times 10^{-11}$ & 46.08 & $92.2 \%$ \\
\hline
\end{tabular}

Notes: ${ }^{a}$ See Figure $14 \mathrm{a} ;{ }^{\mathrm{b}} \mathrm{C}=3.6 \times 10^{15}$ and $m=5$, from S-N curves for riveted structures with detail category $71 ;{ }^{\mathrm{c}}$ Fatigue damage reduction from non-retrofitted case.

\subsection{Results of Sub-Model}

Based on bridge construction drawings, cross-beams are constructed by plates with different sizes connected by pre-stressed rivets. In this section, the global model (without retrofit system) will be subjected to S1 train with the load model shown in Figure 16. As mentioned before, the riveted joint is from mid-span of the first cross-beam (i.e., in the middle of bridge, see Figures 9 and 14b).

Figure 16. S1 train load model.

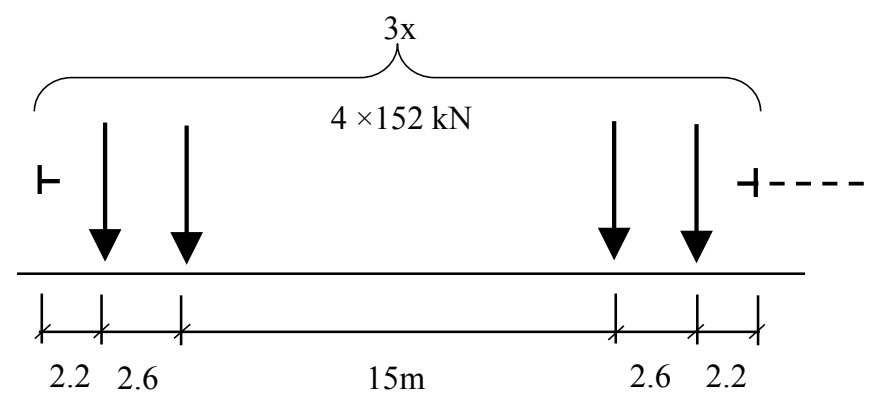




\subsubsection{Effect of Rivet Clamping Force}

Figure 17 shows the state of stress distribution at the vicinity of the rivet hole (under the rivet head) along different directions. The area under the rivet head remains in compression throughout the train passage. This is due to the effect of rivet clamping force which compresses multiple plates simultaneously considering friction between different elements.

Figure 17. (a) Location of the hole; (b) normal stress along $x$ direction (S11); (c) Normal stress along $y$ direction (S22); and (d) Normal stress along $z$ direction (S33). Note: $\mathrm{e}+x$ is equivalent to $10^{+x}$.

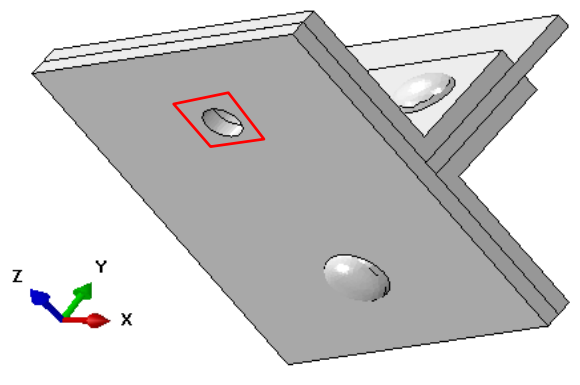

(a) Position of rivet hole

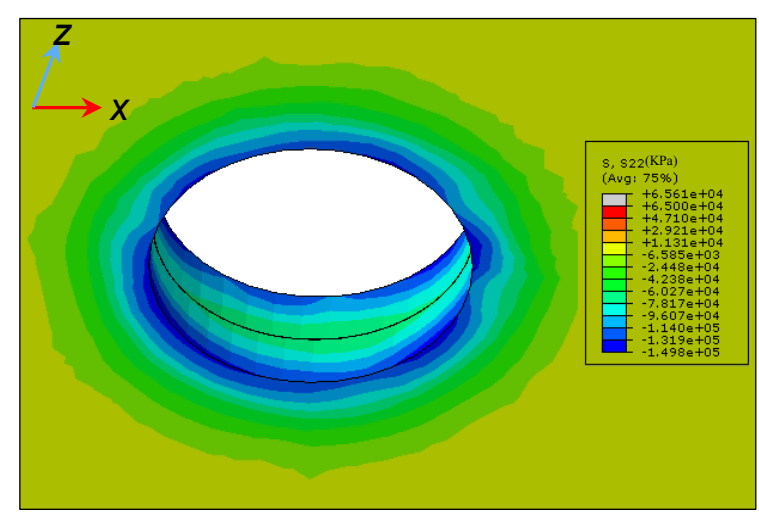

(c) Normal stress along $y$ direction (S11)

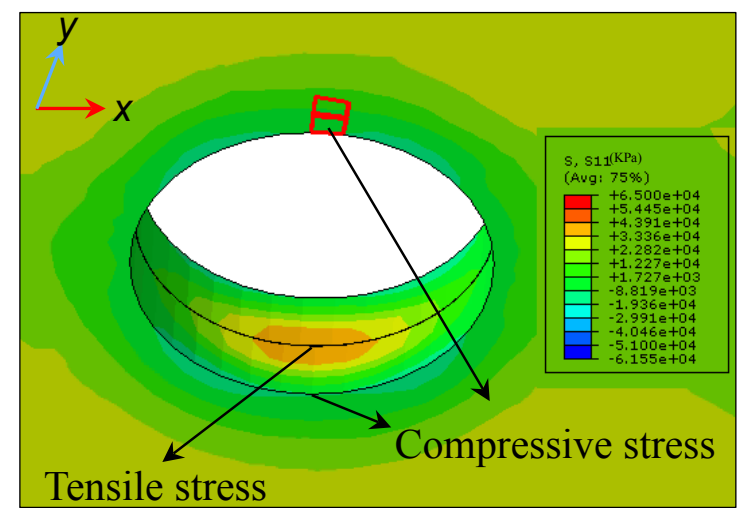

(b) Normal stress along $x$ direction (S11)

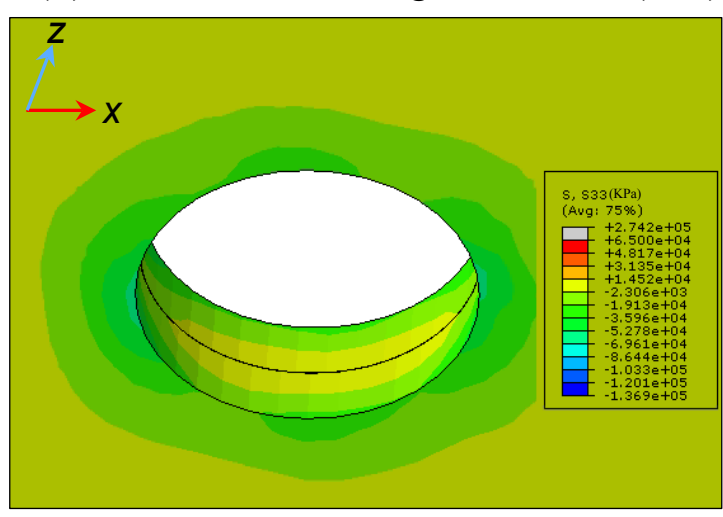

(d) Normal stress along $z$ direction (S33)

\subsubsection{The Most Critical Location for Fatigue Cracking}

Normal stress in the $x$ direction (S11) is used to identify the most critical location for fatigue cracking because the cross-beams are mainly loaded in this direction during the passage of trains. From Figure 17b, it is found that the largest normal stress occurs at the edge of the hole in the interface between two plates at the bottom flange of the cross-beam. This point is the most critical location for fatigue cracking and once the crack is initiated, it propagates perpendicular to the rivet hole (i.e., mainly dominated by mode-I fracture, as shown in Figure 18 by a black line). Thus, it is not easy to identify this type of crack visually since it is hidden between two plates. Figure 19a shows that the stress history at the edge of the rivet hole remains in compression throughout the passage of the train. The exact location of the measurement is indicated by a red cube in Figure 17b. The initial compression is about $-50 \mathrm{MPa}$ which is due to the initial clamping force in the rivet. Figure $19 \mathrm{~b}$ 
compares the results between the global model and the sub-model for the position shown in Figure $18 \mathrm{~b}$ (i.e., the element at the edge of the hole on the interface of the two plates where it has the highest risk of fatigue cracking). The presence of the rivet hole creates a stress concentration factor of about $\Delta \sigma_{1} / \Delta \sigma_{2}=2.26$. For an empty hole (without rivet), the stress concentration factor is 2.48 [15], which is slightly bigger than the case with a pre-stressed rivet. Note that determination of fatigue damage reduction using the sub-modeling results is not possible by the presented method. Other methods, such as the constant life diagram (CLD) approach shall be used.

Figure 18. (a) Riveted joint without outer plate; and (b) Direction of the possible fatigue crack growth. Note: $\mathrm{e}+x$ is equivalent to $10^{+x}$.

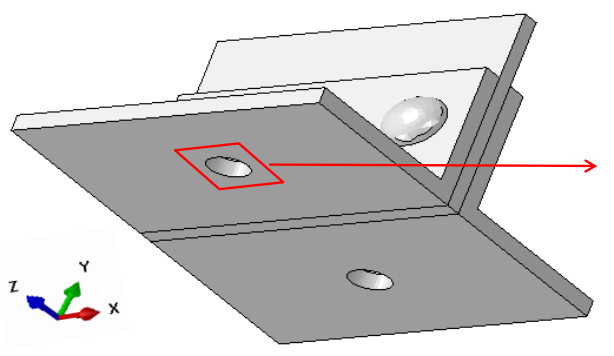

(a)

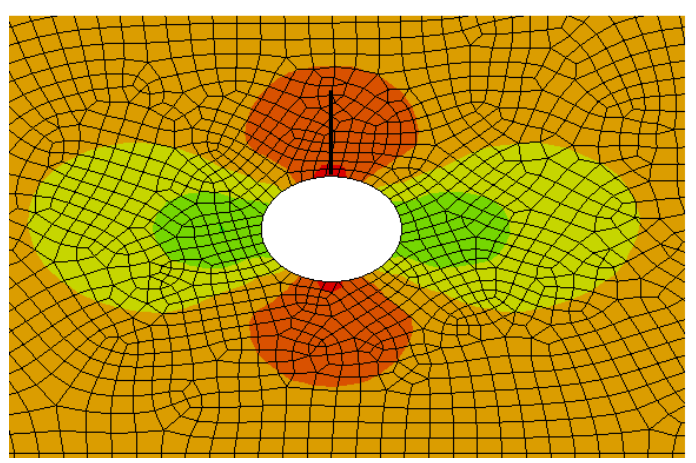

(b)

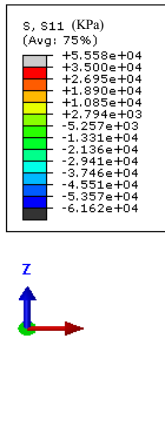

Figure 19. Stress history at rivet edge (a) at outer surface; and (b) at the interface between the two plates.

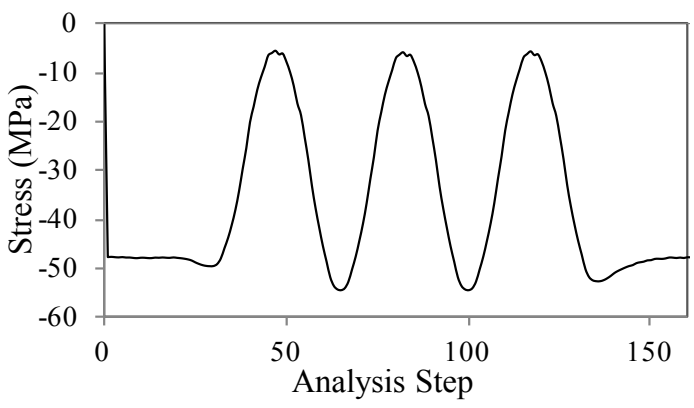

(a)

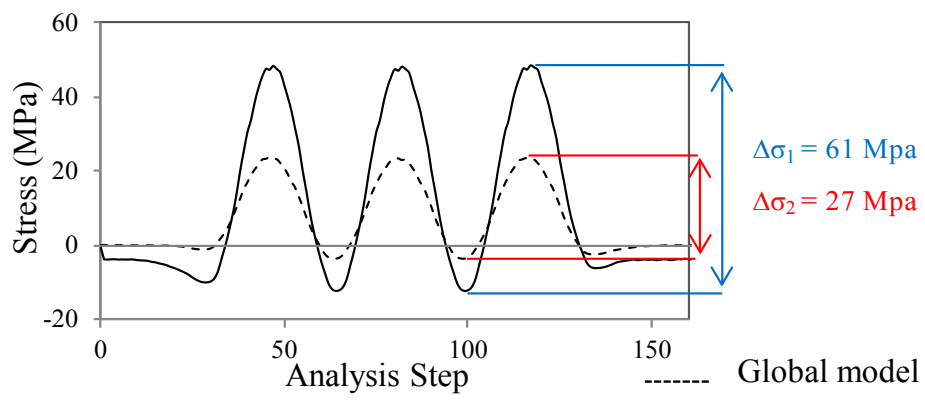

(b) Sub-model

\section{Discussion on the Effect of Fully Compressive Cyclic Loads on Crack Initiation}

Ghafoori et al. [1,16] have shown that for a steel beam with an existing crack, by providing sufficient CFRP pre-stress level the crack tip remains in compression and the fatigue crack growth (FCG) can be arrested. However, there are several other studies (e.g., [17-19]) that reported fatigue crack initiation and propagation even under fully compressive cyclic loads. In all of these studies, the metallic specimen with an existing notch has been first subjected to a compressive pre-load that creates plastic deformation at the vicinity of the notch tip. During unloading, this area develops a residual tensile stress field. At the subsequent compressive cyclic loadings, the crack is initiated from the notch tip and will propagate at a diminishing rate. Once the crack tip is out of the residual tensile stress field, the FCG is arrested. Note that these experiments also show that the cause of mode-I fatigue crack 
initiation and propagation is residual tensile stresses due to initial yielding at the first cycle. Nonetheless, based on Eurocode [14] and Swiss code [13], even if the metallic member is subjected to fully compressive stress below yielding, $60 \%$ of stress range shall be taken into account. It seems that the idea behind such a formula is not to represent the exact physical phenomenon, but rather to create a kind of safety factor. For example, since it is difficult to determine the real level of permanent stresses, to account for all construction phases, a kind of safety is built into the formula by taking $60 \%$ of the compressive part into account.

\section{Conclusions}

Global FE model with mesh refinements within the connection regions were used to identify fatigue critical locations, and to gain insight into the retrofit effects. The following conclusions are based on the bridge analyses:

(1) The most fatigue critical locations among the longitudinal-to-cross beam connections and the cross-beam bottom flanges were determined, with the cross beam bottom flanges being relatively more critical.

(2) Application of an initial compression in metal using pre-stressed CFRP plates has negligible effect on the stress range. The delay in crack initiation phase is achieved through the decrement of the stress ratio (mean stress).

(3) As expected, increased amount of CFRP pre-stress resulted in decreased fatigue damage at all bridge locations.

(4) With an applied $40 \% \sigma_{u}$ CFRP pre-stress, more than $87 \%$ and $85 \%$ reductions in fatigue damage are calculated at the longitudinal-to-cross beam connections and cross-beam bottom flanges, respectively.

(5) The pre-stressed CFRP retrofit has a lower positive effect on fatigue damage reduction at the longitudinal-to-cross beam connection compared to the cross beam bottom flanges (45\% reduction versus $60 \%$ reduction at a $20 \% \sigma_{u, C F R P}$ pre-stress level) due to deformation induced stresses from the longitudinal members.

(6) The results from riveted joint sub-model showed the most fatigue prone location to be on the edge of the rivet hole at the interface of two steel plates.

\section{Acknowledgments}

The study has been supported by the Swiss Commission of Technology and Innovation (CTI) (grant No. 12993.1 PFIW-IW). Financial and technological supports from S\&P Clever Reinforcement AG Company and Swiss Federal Railways (SBB) are also acknowledged.

\section{Author Contributions}

The work is part of Ph.D. studies of the first author supervised by Alain Nussbaumer, Masoud Motavalli and Mario Fontana. The modeling and on-site measurements were mainly conducted by Gary S. Prinz, Emmanuel Mayor and Elyas Ghafoori. 


\section{Conflicts of Interest}

The authors declare no conflict of interest.

\section{References}

1. Ghafoori, E.; Motavalli, M.; Botsis, J.; Herwig, A.; Galli, M. Fatigue strengthening of damaged metallic beams using prestressed unbonded and bonded CFRP plates. Int. J. Fatigue 2012, 44, 303-315.

2. ABAQUS Standard User's Manual, Version 6.4; Hibbitt, Karlsson, and Sorensen Inc.: Pawtucket, RI, USA, 2004.

3. Vassilopoulos, A.P.; Manshadi, B.D.; Keller, T. Piecewise non-linear constant life diagram formulation for FRP composite materials. Int. J. Fatigue 2010, 32, 1731-1738.

4. Ghafoori, E.; Asghari, M. Dynamic analysis of laminated composite plates traversed by a moving mass based on a first-order theory. Compos. Struct. 2010, 92, 1865-1876.

5. National Cooperative Highway Research Program (USA). Dynamic Impact Factors for Bridges, NCHRP Synthesis 266; National Academy Press: Washington, DC, USA, 1998.

6. Smith, I.; Lestuzzi, P. Dynamique des Structures, Polycopié du Cours; EPFL: Lausanne, Switzerland, September 2011.

7. Zhou, Y. Fatigue Strength Evaluation of Riveted Bridge Members. Ph.D. Thesis, Lehig University, Bethlehem, PA, USA, May 1994.

8. Imam, B.M.; Righiniotis, T.D.; Chryssanthopoulos, M.K. Numerical modelling of riveted railway bridge connections for fatigue evaluation. Eng. Struct. 2007, 29, 3071-3081.

9. Basseti, A. Lamelles Précontraintes en Fibres Carbone Pour le Renforcement de Ponts Rivetés Endommagés par Fatigue; Thèse N 2440, ICOM; EPFL: Lausanne, Switzerland, 2001.

10. Zhou, Y.E.; Yen, B.T.; Fisher, J.W.; Sweeney, R.A.P. Examination of fatigue strength (Sr-N) curves for riveted bridge members. In Proceedings of the 12th Annual Bridge Conference, Montreal, Canada, 1995; pp. 102-109.

11. European Community (EC). Guidline for Load and Resistance Assessment of Existing European Railway Bridges; European Commission Sixth Framework Programme, Sustainable Bridges: Malmö, Sweden, 2007.

12. Strain Checker FGMH-1. Tokyo Sokki Kenkyujo Co., Ltd.: Tokyo, Japan, 2005.

13. SIA 269/3-Existing Structures: Steel Structures; Swiss Society of Engineers and Architects (SIA): Zurich, Switzerland, 2011.

14. Eurocode_3. Design of Steel Structrues-Part 1-9: Fatigue; European Standard EN 1993-1-9: Brussels, Belgium, 1993.

15. Budynas, R.G.; Nisbett, J.K. Shigley's Mechanical Engineering Design, 8th ed.; McGraw-Hill: Singapore, 2008.

16. Ghafoori, E.; Schumacher, A.; Motavalli, M. Fatigue behavior of notched steel beams reinforced with bonded CFRP plates: Determination of prestressing level for crack arrest. Eng. Struct. 2012, 45, 270-283. 
17. Hermann, R. Fatigue crack growth in ductile materials under cyclic compressive loading. Fatigue Fract. Eng. Struct. 1994, 17, 93-103.

18. Koichi K.; Takahiro S.; Souichi K.; Tetsuo S.; Kazumune K.; Tadashi S. Fatigue crack growth under compressive loading. J. Nucl. Mater. 1998, 258-263, 2059-2063.

19. Fleck, N.A.; Shin, C.S.; Smith, R.A. Fatigue crack growth under compressive loading. Eng. Fract. Mech. 1985, 21, 173-185.

(C) 2014 by the authors; licensee MDPI, Basel, Switzerland. This article is an open access article distributed under the terms and conditions of the Creative Commons Attribution license (http://creativecommons.org/licenses/by/3.0/). 